University of Louisville

ThinkIR: The University of Louisville's Institutional Repository

Electronic Theses and Dissertations

$5-2015$

\title{
Characterization of the innate response to the RagB protein of Porphyromonas gingivalis.
}

Justin Hutcherson

University of Louisville

Follow this and additional works at: https://ir.library.louisville.edu/etd

Part of the Immunology and Infectious Disease Commons, and the Microbiology Commons

\section{Recommended Citation}

Hutcherson, Justin, "Characterization of the innate response to the RagB protein of Porphyromonas gingivalis." (2015). Electronic Theses and Dissertations. Paper 2077.

https://doi.org/10.18297/etd/2077

This Doctoral Dissertation is brought to you for free and open access by ThinkIR: The University of Louisville's Institutional Repository. It has been accepted for inclusion in Electronic Theses and Dissertations by an authorized administrator of ThinkIR: The University of Louisville's Institutional Repository. This title appears here courtesy of the author, who has retained all other copyrights. For more information, please contact thinkir@louisville.edu. 


\title{
CHARACTERIZATION OF THE INNATE RESPONSE TO THE RAGB PROTEIN OF PORPHYROMONAS GINGIVALIS
}

\author{
Justin Hutcherson
}

A dissertation submitted to the faculty of the School of Medicine of the University of Louisville in partial fulfillment of the Requirement for the degree of

\author{
Doctor of Philosophy \\ In Microbiology and Immunology \\ Department of Microbiology and Immunology \\ University of Louisville \\ Louisville, KY
}

May 2015 
Copyright 2014 by Justin Aaron Hutcherson All rights reserved 



\title{
CHARACTERIZATION OF THE INNATE RESPONSE TO THE RAGB PROTEIN OF PORPHYROMONAS GINGIVALIS \\ By
}

\author{
Justin Hutcherson
}

A Dissertation approved on December $19^{\text {th }} 2014$

by the following Dissertation Committee

David A Scott, Ph.D. (Dissertation Director)

Jill Suttles, Ph.D. (Co-mentor)

Richard Lamont, Ph.D.

Richard Miller, Ph.D.

Jonathan Warawa, Ph.D. 


\section{ACKNOWLEDGMENTS}

First and foremost, I would like to thank my mentor and dear friend for his patience and unconditional support, Dr. David Scott. Under his guidance, I have become a better person an am well on my way to becoming an independent scientist. He has shown great patience and unconditional support for me during my training in his lab. I hope to shine a bright light on his mentorship with my future career in science.

I would like to thank my lab members Diane, Iris and Juhi. I would not have been able to accomplish anything without their help both in and out of the lab. The have become my family, and I will forever be grateful for their love and support.

I would like to thank the labs in the Dental school, particularly the Wang, Lamont and Potempa labs, for being so generous with their reagents, equipment and knowledge in troubleshooting protocols. Dr. Huizhi Wang has taught me many techniques and shared useful insights during my PhD training. Barbara Potempa has been extremely helpful and always takes time to discuss any issues that I may have had.

I would like to thank my dissertation committee for all of their advice: Dr. Jill Suttles, Dr. Richard Miller, Dr. Richard Lamont and Dr. Jonathan Warawa. Dr. Suttles has been extremely supportive and given great insight into immunological aspects of my project. Dr. Miller is one of the greatest assets to the department and his door is always open for students to discuss problems that may arise during their PhD training. Dr. Lamont has been a great resource on multiple projects and always helpful. Dr. Warawa 
has given me many great ideas and advice on problems I have encountered during my project.

I would also like to thank all the faculty, staff and students in the Microbiology

and Immunology, Oral Health and Systemic Disease departments for all their advice and help during my time at Louisville.

Lastly, I would like to thank my family and friends for all of their encouragement and support. For my wonderful mom, who is the sole reason for my success, for her unyielding support and for raising me with a love for education. I am very fortunate to be surrounded by such great people.

Sincerely, Justin 


\begin{abstract}
CHARACTERIZATION OF THE INNATE RESPONSE TO THE RAGB PROTEIN OF PORPHYROMONAS GINGIVALIS

By

Justin Hutcherson
\end{abstract}

December $19^{\text {th }} 2014$

More than 64 million people in the US suffer from some form of periodontal disease. Periodontal diseases are bacterial infections of the hard and soft tissues surrounding the teeth which can lead to tooth loss. Periodontal tissue destruction is caused by inflammatory host-pathogen interactions. Porphyromonas gingivalis is a major causative agent of periodontal diseases and is a keystone periodontal pathogen. The 55kDa immunodominant RagB outer membrane protein of $P$. gingivalis has been proposed to facilitate iron transport. However, potential interactions between RagB and the innate response have not been examined. RagB homologues in gut Bacteroidetes have been associated with inflammatory bowel disease. Therefore, we hypothesized that RagB aids in virulence of $P$. gingivalis and elicits a pro-inflammatory host response in innate cells.

We determined that RagB exposure led to the differential and dose-related expression of multiple genes encoding pro-inflammatory mediators (IL-1 $\beta$, IL-6, IL-8, 
and CCL2) in primary human monocytes and to the secretion of TNF, IL-6 and IL-8. RagB was shown to be a TLR2 and TLR4 agonist that activated STAT4 and NFkB transcription factors. $\triangle \mathrm{rag} B$ mutants also induced a reduced inflammatory response compared to the wild type strain as well as reduced survivability when exposed to oral epithelial cells which adds evidence to the role of $\operatorname{rag} B$ in epithelial cell colonization. These results suggest that $\mathrm{rag} B$ elicits a major pro-inflammatory response in primary human monocytes and therefore could play an important role in the etiology of periodontitis and systemic sequelae. 


\section{TABLE OF CONTENTS}

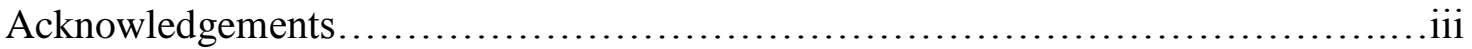

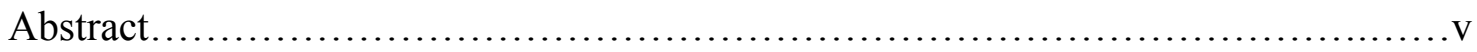

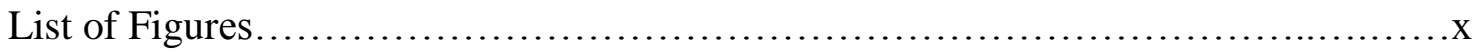

List of Tables.......................................................................

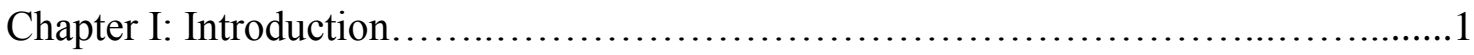

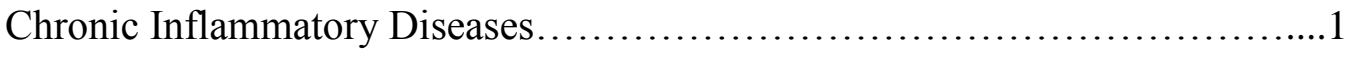

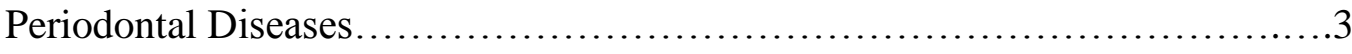

Porphyromonas gingivalis ................................................. 5

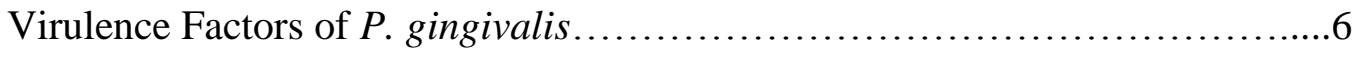

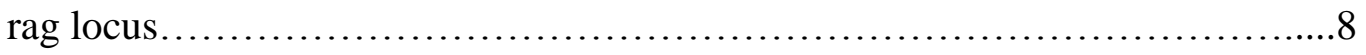

Innate Immune Response..............................................11

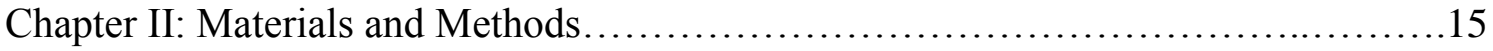

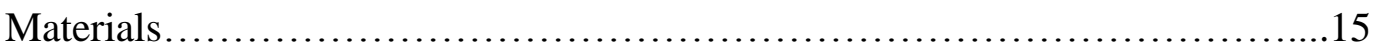

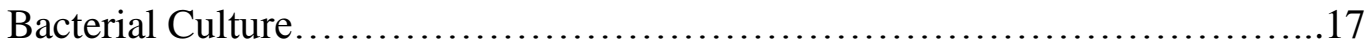

Isolation and maintenance of human cells...................................17

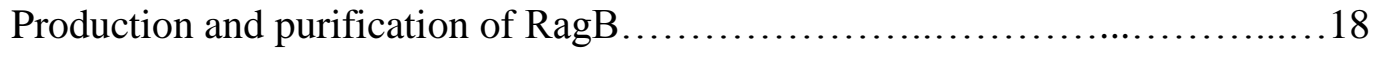

RagB stimulation of IL-8 and NFkB in THP-1 cells..........................19

RagB stimulation of cytokines from TLR-transfected HEK-293 cells..........19 
Quantification of RagB induced cytokines in primary monocytes..............20

Identification of genes activated by RagB in a qRT-PCR TLR array...........20

Identification of genes activated by RagB in primary human monocytes by whole

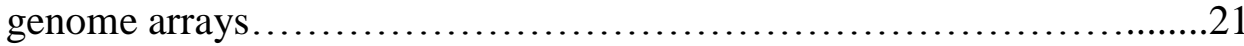

qRT-PCR validation of RagB-regulated genes...............................22

TLR specificity of RagB in primary human monocytes.....................23

Inhibition of STAT4 in RagB-stimulated primary human monocytes.............23

Inhibition of NFkB (p65) in RagB-stimulated primary human monocytes.........23

TLR2, TLR4, p65 and STAT4 gene silencing............................24

Colonization of epithelial cells by wildtype and $\triangle \operatorname{rag} B P$. gingivalis strains.....24

Induction of cytokines by wildtype and $\triangle \operatorname{rag} B P$. gingivalis in monocytes.........25

Preparation of RagB for crystallization.................................25

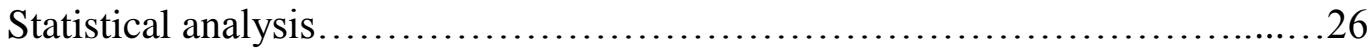

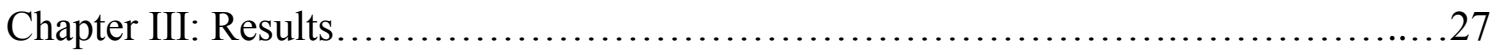

RagB production and purification....................................27

RagB does not elicit a response in THP-1 and HEK transfected cell lines.......29

RagB induces pro-inflammatory cytokines in primary human monocytes......34

RagB induces multiple pro-inflammatory genes in TLR-focused arrays...........36

RagB induces multiple pro-inflammatory genes in dose-dependent manner in

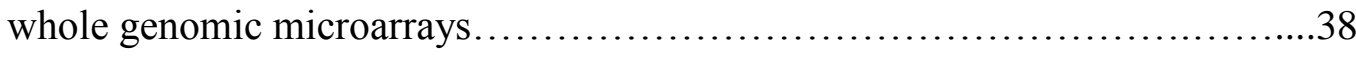

RagB induction of IL-8 is TLR2-dependent...........................41

RagB induction of IL-8 is TLR4-dependent............................43

RagB induction of IL-8 is STAT4-dependent...........................44 
RagB induction of IL-8 is NF- $\kappa \mathrm{B}(\mathrm{p} 65)$-dependent.......................47

RagB induces phosphorylation of STAT4 and p65.......................49

$\Delta \operatorname{rag} B$ mutant induces weaker inflammatory response than wildtype

$P$. gingivalis.................................................50

$\Delta r a g B$ mutants are unable to colonize TIGKs...........................52

Confocal microscope analysis of $P$. gingivalis $\triangle \mathrm{rag} B$ inability to colonize

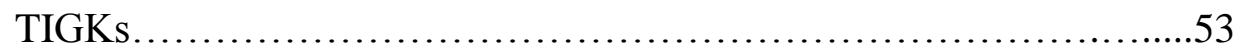

RagB crystal structure..............................................55

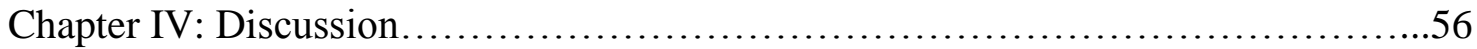

Chapter V: Therapeutic Directions.........................................62

Ongoing Investigations.............................................62

Pharmacological approaches......................................62

Implications of a $\mathrm{rag} B$ vaccine....................................63

Crystal structure analysis...........................................65

Virulence models of $P$. gingivalis ..........................................65

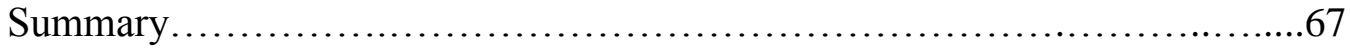

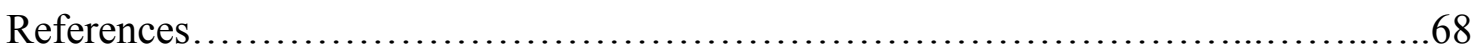

Curriculum Vitae....................................................... 77 


\section{LIST OF FIGURES}

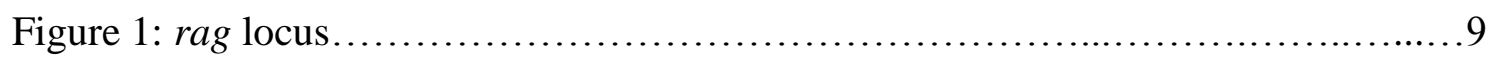

Figure 2: Activation of the NF-kB pathway by TLR2 and $-4 \ldots \ldots \ldots \ldots \ldots \ldots \ldots \ldots \ldots \ldots$

Figure 3: Purified RagB run on a NuPAGE® Novex® 4-12\% Bis-Tris Gel..............28

Figure 4: Denatured RagB does not elicit a IL-8 response...........................29

Figure 5: RagB does not induce an IL-8 response in THP-1 cells......................31

Figure 6: RagB does not induce NFאB in THP-1XBlue cell line.......................32

Figure 7: RagB does not signal through surface exposed TLRs in HEK cell lines..........33

Figure 8: RagB induces pro-inflammatory cytokines in primary innate cells............35

Figure 9: Pathway analysis of the top differently regulated genes in relationship with

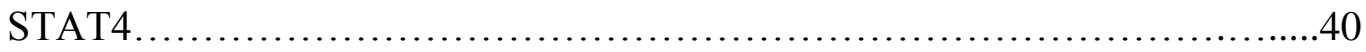

Figure 10: RagB induction of IL-8 is TLR2-dependent............................42

Figure 11: RagB induction of IL-8 is TLR4-dependent.............................44

Figure 12: RagB induction of IL-8 is STAT4-dependent............................46

Figure 13: RagB induction of IL-8 is NFkB (p65)-dependent.........................48

Figure 14: RagB induces the phosphorylation of STAT4 and p65 ...................49

Figure 15: $\triangle \mathrm{ragB}$ mutant induces weaker inflammatory response than wild type

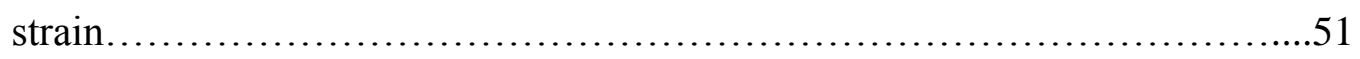

Figure 16: $\triangle \mathrm{ragB}$ mutant exhibits lower colonization rate than wild type in

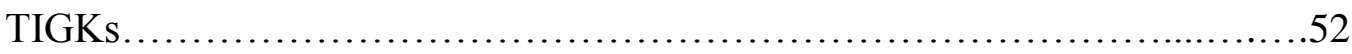


Figure 17: $\mathrm{rag} B$ appears to play a role in colonization of TIGKs...................54

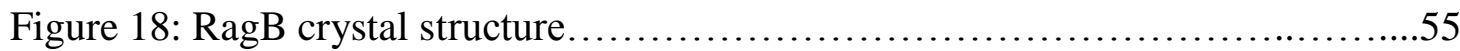




\section{LIST OF TABLES}

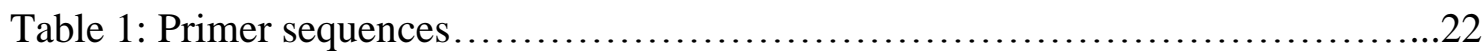

Table 2: RagB induces multiple TLR-related genes in primary human monocytes.....37

Table 3: LPS induces multiple TLR-related genes in primary human monocytes.......37

Table 4: RagB induces multiple pro-inflammatory genes in dose-related

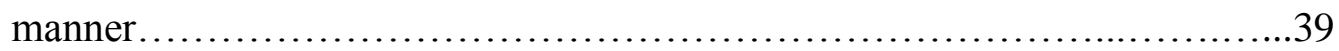




\section{CHAPTER ONE: INTRODUCTION}

\section{Chronic Inflammatory Diseases}

The innate immune response must be tightly regulated and able to distinguish between foreign and domestic antigens. Pathogens elicit innate responses but when the pathogen has been cleared the response must be turned off to prevent host cell and tissue destruction. The central nervous system (CNS) regulates a feedback loop that optimizes innate inflammatory responses. Glucocorticoids are anti-inflammatory molecules that are released to terminate inflammation. The $\mathrm{NF \kappa B}$ pathway can be shut off by the interaction of RelA (p65) with glucorticoids, which induce IkB and stop the production of proinflammatory cytokines [1]. If the response is left unchecked, then this can lead to the disruption of homeostasis and result in autoimmune diseases, cancers, septic shock and multiple chronic inflammatory diseases [2].

According to the CDC, 7 out of 10 people in the US die of a chronic disease. Chronic inflammatory diseases are defined as long term inflammatory processes that are directed at particular endogenous or exogenous stimuli. Pathogens that are able to persist and avoid being destroyed by the host can lead to the progression of chronic inflammation. Diet and lifestyle also play a major role in chronic inflammatory diseases [3]. Obesity, which affects more than one third of adults in the US, is a risk factor for chronic inflammatory disease. With the increase in fat cells, the output of inflammatory 
molecules is increased and this can result in insulin resistance leading to diabetes and other diseases [4].

Chronic inflammation leads to many chronic diseases including inflammatory bowel disease (IBD), periodontitis, type I diabetes, stroke, and many other chronic conditions. There are many studies investigating strategies to control and down regulate inflammatory responses. A major target for anti-inflammatory therapeutic treatment is the transcription regulator, $\mathrm{NF} \kappa \mathrm{B}$. NFאB plays a central role in inflammatory processes and numerous papers have shown NFkB to be a potential therapeutic agent for chronic inflammation [5-7]. For example, resveratrol, a natural polyphenol associated with antiinflammatory effects, has been shown to inhibit the progression of Alzheimer's disease by interfering with TLR4/NFkB/STAT pathways [8]. Other transcriptional pathways are being investigated to be used for anti-inflammatory therapies. Signal transducer and activator of transcription 4 (STAT4) is a major inflammatory mediator. STAT4 has been shown to be necessary in the differentiation of B cells [9] and regulatory T cells [10]. STAT4 plays a significant role in autoimmune diseases such as rheumatoid arthritis [11], inflammatory bowel disease [12], and type I diabetes [13]. STAT4 is a target of lisofylline (LSF) for anti-diabetic effects [14] which has been shown to inhibit STAT4 activation through IL-12 signaling. Lisofylline has also been shown to be useful in the prevention of type 1 diabetes in C57BL/6 mice [15]. 


\section{Periodontal diseases}

Chronic periodontitis, characterized by the destruction of the hard and soft tissues surrounding the teeth, is predominantly caused by the immune response to pathogenic bacteria present in the dental plaque. Periodontitis and gingivitis are periodontal diseases that contribute to a major economic burden worldwide. According to the World Health Organization, $>60 \%$ of the population aged 35-44 years of age in the Americas have some form of periodontitis [16]. Gingivitis is a periodontal disease that is characterized by inflammation around the teeth, and if left untreated can lead to periodontitis. The economic burden of periodontal diseases in the US is more than $\$ 14$ billion per annum [17]. More than 50\% of the population in the US will have some form of periodontal disease in their lifetime [18]. People over the age of 60 have a greater than $65 \%$ chance of having periodontitis. More than 64 million people in the US have some form of periodontitis [19].

There are many risk factors that contribute to periodontal diseases. Poor oral hygiene, immunodeficiency, age, diabetes [20] and smoking [21] are all factors that can increase susceptibility to periodontal diseases $[22,23]$. Smoking is a major risk factor for multiple diseases, in part, due to the massive number of carcinogens and toxins found in tobacco and tobacco smoke. Smoking is the greatest environmental risk factor for periodontal diseases. Smokers display a more severe form of periodontitis and are more refractory to treatment than non-smokers $[24,25]$. Smoking also leads to a pathogenenriched oral microbiota [26]. 
Tissue destruction is caused by a combination of bacterial insult and the host immune response to dental plaque. Host cells release cytokines, proteases, and other factors which both combat pathogens and destroy tissue and host cells. Bacteria, on the other hand, utilize an array of factors, such as the release of enzymes and toxins to increase their survivability in the host, some of which can cause host tissue destruction.

The microbiome of healthy individuals consists of mainly aerobic Gram-positive bacteria, with a shift towards anaerobic Gram-negative bacteria noted in the diseased state [27]. Bacteria are able to colonize the junction between the tooth and oral epithelium and form biofilms, which make up dental plaque and lead to dental caries. Dental plaque consists of bacterial communities that lead to the destruction of enamel on the tooth by the release of metabolites produced from the breakdown of sugars by the bacteria. Once the enamel is destroyed, dentin is exposed and bone destruction occurs more rapidly. Bacterial biofilms protect the bacteria from host responses and allow bacteria to persist and further colonize the host. Biofilms contain specific niches that allow for a diversity of bacteria to survive. These environments provide nutrient gradients, various $\mathrm{pH}$ levels, and aerobic-anaerobic environments. Biofilms also protect from phagocytosis and antibiotics [28, 29].

Periodontal diseases are a risk factor for an array of diseases such as stroke [30, 31], pulmonary diseases [32, 33], rheumatoid arthritis [34], and pre-term birth [35-37]. Traditionally, the major causative agents of periodontal diseases were the "red complex" which included Tannerella forsythia, Treponema denticola and Porphyromonas gingivalis [38]. This concept has been recently superseded by the "keystone pathogen" hypothesis. Keystone pathogens are those of relatively low number within the 
microbiome which cause a disruption in the symbiosis of the normal flora leading to a more pathogenic state [39]. P. gingivalis has evolved strategies to impair the innate immunity by altering the entire biofilm and disrupting homeostatic host-microbial interactions in the periodontium $[39,40]$.

\section{Porphyromonas gingivalis}

Porphyromonas gingivalis, a Gram-negative, assaccharolytic anaerobe, is a causative agent of chronic periodontitis and a keystone pathogen of the sub-gingival biofilm [41]. P. gingivalis has also been associated with other diseases such as diabetes [20], rheumatoid arthritis [34], and other chronic inflammatory diseases [42].

$P$. gingivalis employs many factors in its colonization of the oral cavity including the secretion of proteinase enzymes called gingipains that are capable of degrading host cell receptors, complement proteins, and other host components [43]. P. gingivalis is also very efficient in forming biofilms. Biofilms play a major role in the colonization of the oral cavity allowing bacteria to form specialized niches. Anaerobes are protected from oxygen rich environments by aerobic bacteria that are found on the outer layers of the biofilm. Biofilms also protect bacteria against antibiotics and against phagocytosis by host immune cells. Dental plaque is a bacterial biofilm that forms on the surface of the tooth and epithelium aiding the oral pathogens in disease progression.

Because $P$. gingivalis is assaccharolytic, it is unable to break down carbohydrates for energy, therefore, it needs to acquire nutrients from the environment [44]. $P$. gingivalis is able to obtain amino acids from the subgingival environment due to secretion of proteases, along with other oral bacterial and host-derived proteases. The 
destruction of connective tissue caused by the inflammatory response leads to a release of nutrients necessary for survival of $P$. gingivalis. Thus, the immune response involuntarily aids $P$. gingivalis survival by providing essential nutrients that would not normally be available.

\section{Virulence Factors of Porphyromonas gingivalis}

$P$. gingivalis has an arsenal of virulence factors which aid in its ability to colonize, establish infection and cause disease. These factors include capsule production, secretion of gingipains, LPS, fimbrial proteins and the rag locus [45].

Capsule: To avoid phagocytosis, some $P$. gingivalis strains produce a negatively charged polysaccharide capsule. There are six capsule serotypes (K1-K6) found in P. gingivalis [46]. The W83 strain used in this study contains the K1 serotype. The extracellular capsule aids the bacteria in the resistance to being engulfed by neutrophils and other phagocytes of the immune system $[47,48]$. A recent study showed a non-encapsulated mutant to be significantly more invasive than the wild type strain in human gingival fibroblasts, allowing it to avoid being killed by antibiotics [49]. Studies have also shown variations between serotypes of encapsulated strains differentially regulate the host immune response. Encapsulated strains had a higher virulence in a mouse abscess model when compared to non-encapsulated strains $[48,50]$. Thus, expression of the polysaccharide capsule may be beneficial for survival within the host both upregulated and downregulated. 
Gingipains: $P$. gingivalis produces three cysteine proteases called gingipains. The gingipains include: RgpA and RgpB which are arginine-specific, and Kgp which is lysine specific [51, 52]. Gingipains are considered housekeeping proteases of $P$. gingivalis since they are able to degrade proteins into peptides which can then be used for growth and metabolism [43]. Gingipains utilize free amino acids as a source of carbon and nitrogen [53]. Gingipains are a major virulence factor that aids in attachment and colonization, evasion of host defenses, and tissue invasion and dissemination. A recent study comparing wild type with a gingipain deficient mutant has showed gingpains play an important role in intracellular survival [54]. Gingipains are also able to degrade multiple complement components and host cell receptors to subvert the immune response $[55,56]$.

LPS: $P$. gingivalis is atypical in that it is structurally different from typical enterobacterial LPS such as that found in E. coli. P. gingivalis LPS contains lipid A heterogeneity containing tetra-(LPS $1435 / 1449)$ and penta-(LPS 1690$)$ acylated forms $[57,58]$. P. gingivalis LPS has been shown to differentially activate TLR4-mediated NFKB which modulates expression of IL-6 and IL-8 in human gingival fibrobasts [59]. P. gingivalis LPS can signal inflammatory cytokines through both TLR2 and $-4[58,59]$. The LPS $_{1435 / 1449}$ tetra form has been shown to weakly activate the immune response, while the LPS $_{1690}$ penta form induces a much stronger inflammatory response [60]. Altering its lipid A structure contributes to $P$. gingivalis' ability to evade the innate host's defenses.

Fimbrial proteins: Fimbriae are fine, numerous appendices that protrude from the outer cell membrane. $P$. gingivalis produces several fimbrial proteins, including the major fimbrial antigen (FimA) and minor fimbrial antigen (Mfa1). Mfa1, $67 \mathrm{kDa}$ protein, are 
shorter filaments (18-120nm) [61] and FimA,41kDa protein, are longer filaments (0.5-1 $\mu \mathrm{m})[62]$. Both are considered virulence factors that aid in adherence and invasion of tissue $[62,63]$. A recent study which used an in vitro biofilm model, showed fimbrial proteins aid $P$. gingivalis in binding to a primary oral colonizer, Streptococcus gordonii [64]. Both types of fimbriae stimulate pro-inflammatory cytokines though distinct TLR2 pathways $[65,66]$. Mfa1 has been shown to target C-type lectin receptors for invasion in monocyte-derived cells [67]. Our lab has shown FimA abrogates the pro-inflammatory response to TLR 2 stimulation by other TLR 2 specific agonists. We have also shown a differential expression of fimbrial proteins in response to the environmental stress of tobacco smoke [65].

\section{$\operatorname{rag}$ locus}

The rag locus of $P$. gingivalis is comprised of receptor antigen A (ragA, PG0185), encoding a $115 \mathrm{kDa}$ TonB-dependent receptor, and ragB (PG0186), encoding a $55 \mathrm{kDa}$ putative lipoprotein (Figure 1) [68]. The rag proteins are homologous to the starch utilization system proteins, SusC and SusD, respectively, of gut Bacteroidetes [69]. The rag genes are co-transcribed, flanked by insertion sequences, and consist of a lower $\mathrm{G}+\mathrm{C}$ ratio than the rest of the genome, suggesting the rag locus is a pathogenicity island that arose from horizontal transfer $[68,70]$.

The exact function of the rag locus has yet to be determined. RagA spans the outer membrane forming a beta-barrel like structure and is believed to be linked to a TonB-like protein, whereas RagB is exposed on the outer surface of the membrane in a complex with RagA [68]. The closest homolog is the Sus system that is involved in the 
transportation and utilization of starch and other complex molecules [70], but it is still unclear of the role the rag locus plays in nutrient acquisition. It has been hypothesized that the rag locus aids iron acquisition since it is analogous to transferrin binding systems found in Neisseria and Haemophilus species which contain a TonB-linked outer membrane protein (i.e. $\operatorname{rag} A$ ) that is cotranscribed with a outermembrane lipoprotein (i.e. $\operatorname{rag} B)[68]$.

While host-RagB interactions are poorly understood, a recent study using $P$. gingivalis cell lysate and serum from patients with periodontitis has shown that RagB is the most immunodominant $P$. gingivalis antigen, and is clearly recognized by the immune system [71]. Recent data suggest that the rag operon may be essential for survival in vitro to $P$. gingivalis using a mariner transposon system [72].

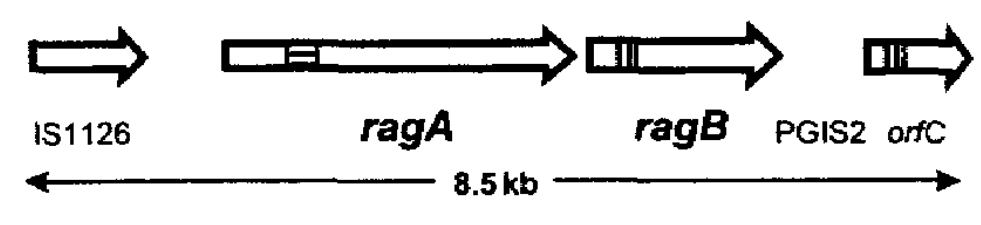

TonB box sites. III Signal sequence motif of lipoproteins.

Figure 1. rag locus. A schematic diagram of the rag locus and flanking genes in $P$. gingivalis [68]. The rag locus consists of $\mathrm{rag} A$ and $\mathrm{rag} B$ genes which are flanked by an insertion sequence (IS1126). $\operatorname{rag} A$ contains a TonB box site and $\operatorname{rag} B$ contains a motif indicative to lipoproteins. 
RagB is frequently found in $P$. gingivalis from periradicular lesions, [73] and is mostly commonly found in the strains isolated by deeper pocket depths using PCR analysis of subgingival plaque samples from periodontal patients and healthy control individuals[68]. This association suggests that rag aids the bacterium in establishing a more severe form of disease due to being found more frequently in deep pockets. rag mutants have been shown to be less virulent in a dorsal subcutaneous mouse model [74, 75]. Ulcer sizes were significantly smaller in mice infected with rag mutants with very few bacteria recovered from the spleen, compared to the wild type [74]. Another group demonstrated rag knockout mutants inoculated by a dorsal subcutaneous infection had a significantly higher survival rate when compared to the wild type strain [75]. This suggests the rag locus could be a major virulence factor in vivo.

RagB is under investigation as a potential periodontitis vaccine. Zheng et.al used eukaryotic expression vector (pIRES) gene-linked to $\operatorname{ragB}$ as a DNA vaccine and showed mice inoculated intramuscularly with a $r a g B$-linked DNA vaccine produced a strong antiRagB antibody response, were strongly resistant to $P$. gingivalis infection and displayed a significant reduction in lesion size compared to the control group [76]. RagB is also considered to play a essential role in the invasion of KB (HeLa-derived continuous cell line) cells based on genomic comparison of invasive and non-invasive strains using genomic hybridization arrays [77]. 


\section{Innate Immune Response}

Humans are constantly exposed to microbes that have the ability to cause infection and disease. The immune system has evolved to recognize and respond to the invading microbes, and to establish long term memory for certain pathogens. The two main arms of the immune system are innate immunity and adaptive immunity, which work in concert to eliminate potential pathogens.

The adaptive immune response involves immune memory and is highly specific for particular pathogen-derived antigens. The innate immune response, on the other hand, relies on its ability to recognize common molecules of invading microbes. Pattern recognition receptors (PRRs) on host cells recognize highly conserved microbeassociated molecular patterns (MAMPs) [78]. Toll-like receptors (TLRs), C-type lectin receptors (CLRs), nucleotide-binding and oligomerization domain (NOD)-like receptors (NLRs) and retinoic acid-inducible gene I-like receptors (RIGs) are all PRRs that are expressed to recognize potential pathogens [79-81]. RIGs, NLRs and some TLRs are intracellular receptors while CLRs and other TLRs are membrane bound surface exposed receptors $[82,83]$.

Humans express ten known TLRs in epithelial, endothelial and leukocyte subtypes. Some TLRs can form complexes with other TLRs such as TLR2, which is capable of forming heterodimers with both TLR1 and -6. Agonists of TLRs include triacyl lipopeptides, dsDNA, LPS, flagellin, diacyl lipopeptides, imidazoquinoline amines, ssRNA, and unmethylated CpG DNA which are recognized by TLR2/1, -3, -4, $5,-2 / 6,-7,-8$ and -9 , respectively. The TLR10 agonist is still unknown [84-86]. The 
major surface TLRs are TLR2/4/5, which are the focus herein. All TLR signaling pathways result in activation of the transcription factor $\mathrm{NF} \kappa \mathrm{B}$ (nuclear factor- $\kappa \mathrm{B}$ ) via the myeloid differentiation primary response 88 (MyD88) or TIR-domain-containing adapter-inducing interferon- $\beta$ (TRIF) (Figure 2). MyD88 and TRIF are the major adaptors that bind to the intracellular domain of TLRs $[87,88]$. TLRs use different combinations of adaptors to activate unique pathways for the elimination of pathogens $[89,90]$. Once a MAMP is recognized by PRRs on innate immune cells, an inflammatory response is elicited at the site of infection. Neutrophils and macrophages/monocytes are primary responders of the innate system. They have the ability to phagocytize antigens and release molecules for the recruitment of additional immune cells and other molecules to destroy the invading microbe [91, 92].

As our immune system has evolved to combat microbes, microbes have adapted strategies of their own to subvert the immune system. Several strategies are utilized in avoidance of the immune system including secretion of proteases to degrade cytokines and host receptors, modification of the molecular structure of their MAMPs to avoid recognition by PRRs and protein secretion systems that deliver virulence factors into the host cells to down regulate immune responses.

Certain pathogens are capable of targeting major signal transduction pathways, including the NFאB and MAPK pathways. Bacillius anthracis lethal factor (LF) directly inhibits MAPK pathways by cleaving the amino terminus on MAPKK1 and -2 [93]. Shigella spp. are capable of surviving within host macrophages where they inhibit the NFאB pro-inflammatory pathway through release of its Type III effector molecule, OspL [94]. Extracellular bacteria such as enterohemorrhagic Escherichia coli (EHEC) also 
inhibit the MAPK-NFאB pathway by releasing translocated intimin receptor (Tir) into the host. Tir mimics immunoreceptor tyrosine-based inhibition motifs (ITIMs), which leads to the recruitment of Src-homology-region-2-domain-containing phosphatase 1 (SHP-1) that directly dephosphorylates NFאB and MAPK [95].

While it has been established that RagB is recognized by the immune system, the inflammatory potential of RagB is unknown. The main objective of this study was to determine the inflammatory potential of $\mathrm{RagB}$ and to unravel any underlying proinflammatory mechanisms. We determined that RagB elicits a pro-inflammatory response, via TLR-2 and -4, and activates transcription factors STAT4 and NFkB, which then leads to production of pro-inflammatory mediators at the transcriptional and protein levels including IL-6, TNF and IL-8. We also add evidence to the important role of ragB in $P$. gingivalis invasion of oral epithelial cells using a $\operatorname{rag} B$ knockout mutant. 


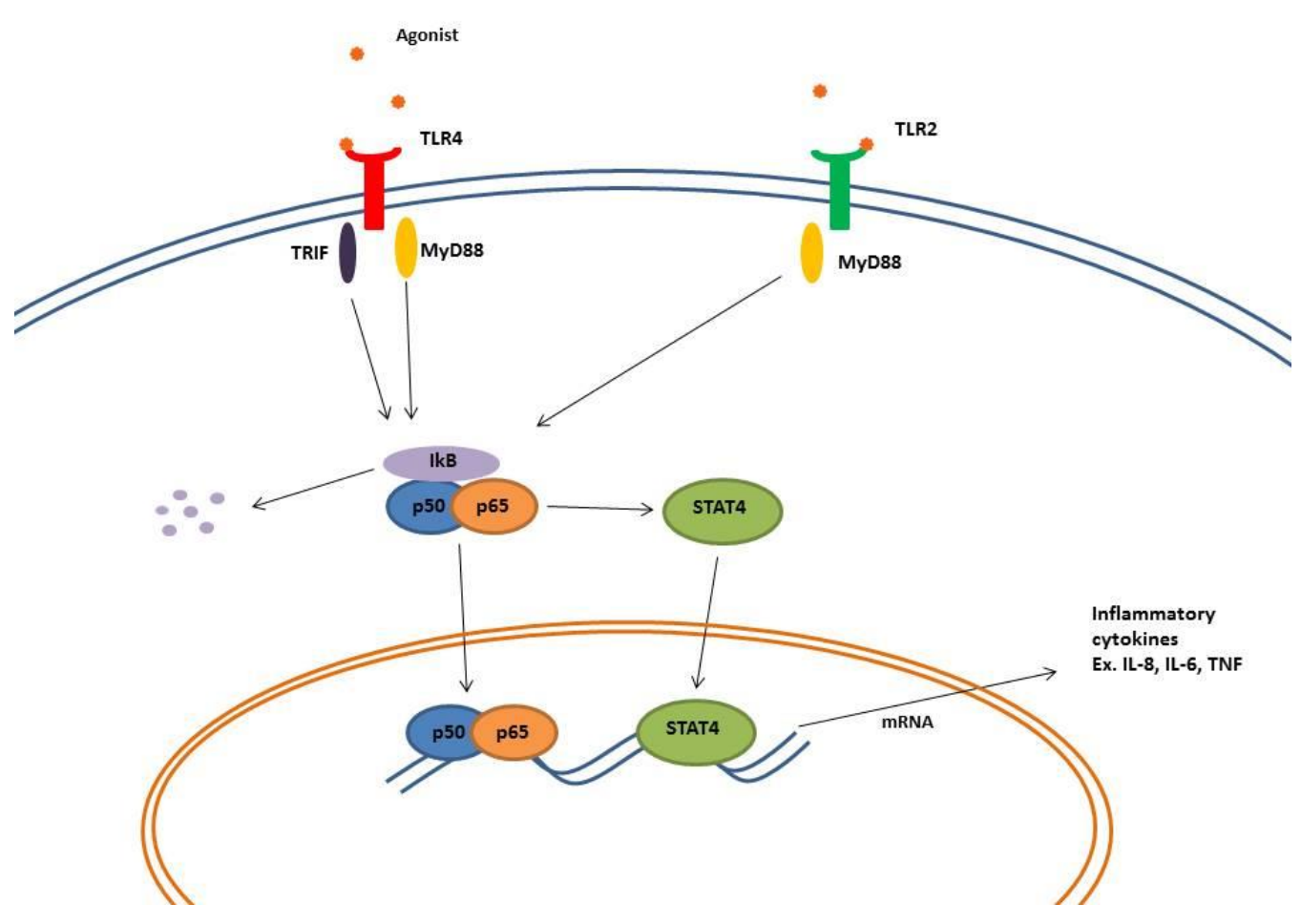

Figure 2. Activation of the NFאB pathway by TLR2 and -4 .

Diagram represents the activation of NFאB complex via surface expressed TLR2 and -4 in a human monocyte. Agonists recognized by TLRs lead to the phosphorylation of IкB which then degrades allowing the p50/p65 complex to travel directly to the nucleus for transcription and/or allow binding to STAT4 which then can activate transcription. 


\section{CHAPTER TWO: MATERIALS AND METHODS}

\section{Materials}

Gifu Anaerobe Medium (GAM) was purchased from Nissui Pharmaceutical (Tokyo, Japan). $\triangle \mathrm{rag} B$ and $\Delta \mathrm{rag} B / W 83$ complement strains were a generous gift from Dr. Fuminobu Yoshimura [74]. P. gingivalis specific antibodies were a kind gift from Dr. Richard Lamont, and the E.coli DH5 $\alpha$ with pSAM was a kind gift from Dr. Debbie Yoder-Himes [96]. Basal media was purchased from Lifeline Cell Technology (Frederick, MD). Sheep blood was purchased from Lampire Biological Laboratories (Pipersville, PA). Nu-PAGE 4-12\% Bis-Tris gels, PBS, RPMI-1640, DMEM, expression plasmid pBAD kit, PCR supermix, EKmax and EKaway resin were purchased from Invitrogen (Carlsbad, CA). LB broth and agar were purchased from BD Biosciences (San Jose, CA). Anti-TLR2 (clone B4H2) and -4 (clone W7C11) antibodies, Quanti-Blue NFאB assays, Hygro-Gold, blasticidin, Normocin, Zeocin, Ultra Pure LPS-EK, Human TLR agonist kit were purchased from Invivogen (San Diego, CA). The anaerobic chamber was bought from Coy Laboratories (Grass Lake Charter Township, MI). Ampicillin, gentamicin, erythromycin, tetracycline, RIPA buffer, phosphatase and proteinase inhibitor cocktails, arabinose, E.coli LPS, metronidazole, HEPES buffer, sodium bicarbonate, sodium pyruvate, streptomycin and phallodin-TRITC stain were purchased from Sigma-Aldrich (St. Louis, MO). Fetal bovine serum (FBS) was 
purchased from Atlanta Biologicals (Flowery Branch, GA). RNA purification kit was purchased from 5-Prime (Gaithersburg, MD). All primers were ordered from Biosynthesis Inc. (Lewiston, TX). ImageQuant LAS 4010, HiTrap Chelating HP column was from GE Healthcare (Piscataway, NJ). Anti-p-p65, p-STAT4, p65, STAT4, $\beta$-actin antibodies were purchased from Cell Signaling Technology (Beverly, MA). Anti-TLR2 and -TLR4 antibodies, siRNA TLR2, TLR4, p65, STAT4 and control were purchased from Santa Cruz Biotechnology (Santa Cruz, CA). Coomassie Blue stain and PVD membrane were purchased from Bio-Rad Laboratories (Hercules, CA). Signaling Pathway RT ${ }^{2}$ Profiler PCR arrays, SYBR Green Supermix with ROX were purchased from Qiagen (Valencia, CA). Quanta cDNA synthesis mix from Quanta BioScience (Gaithersburg, MD). IL-6, -8, IFN $\gamma$, IL-4, 12, TNF Elisas purchased from eBioscience (San Diego, CA). GeneChip ${ }^{\circledR}$ 3' IVT Express kit from Affymetrix (Santa Clara, CA). NanoDrop Spectrophotometer ND-1000 from Thermo Scientifc (Wilmington, DE); (R)lisofylline was purchased from Cayman Chemical (Ann Arbor, MI). p65(Ser276) and control peptide inhibitors were from Novus Biologicals (Littleton, CO). 4-D Nucleofactor system, P3 primary transfection kit were purchased from Lonza (Rockland, ME). CD14 I and II isolation kits were purchased from Miltenyi Biotec (San Diego, CA). Lymphocyte separation medium (LSM), Triton X, 2-mercaptoethanol, 4-chambered slides, Pro-Long Gold with DAPI stain were purchased from Fisher Scientific (Pittsburgh, PA). Genomic DNA isolation kits were purchased from Promega (Madison, WI). Fluoview FV1000 confocal system was purchased from Olympus (Center Valley, PA). $1 \%$ paraformaldehyde solution was purchased from Electron Sciences Microscopy (Hatfield, PA). ABI 7500 Real-Time PCR machine from Applied Biosystems, 
Supersignal West Pico Chemiluminescent substrate, Slide-A-Lyzer Dialysis Cassette, 10K MWCO, trypan blue and BCA Protein Assay kit were purchased from Thermo Fisher Scientific (Rockford, IL).

\section{Bacterial culture}

Porphyromonas gingivalis strains W83 and 33277 were purchased from American Type Culture Collection (Manassas, VA) and maintained in GAM broth. $\Delta r a g B$ and pTCBex2:ragBW83-carrying complemented $P$. gingivalis strains have been described previously [74]. P. gingivalis strains were maintained in a Coy Laboratories anaerobic chamber $\left(80 \% \mathrm{~N}_{2}, 10 \% \mathrm{H}_{2}, 10 \% \mathrm{CO}_{2}\right)$ at $37^{\circ} \mathrm{C}$. E.coli $\mathrm{TOP} 10$ strain was maintained aerobically in LB broth or LB agar plates at $37^{\circ} \mathrm{C}$. Purity of bacterial cultures were routinely screened by Gram stain.

\section{Isolation and maintenance of human cells}

Whole blood was isolated from healthy donors ( $\geq 18$ years; $\geq 49.9 \mathrm{~kg}$; free of any chronic health problems; medication free; not pregnant) who provided written, informed consent as approved by the Institutional Research Board at the University of Louisville. Buffy coat was collected from an LSM gradient, washed in PBS (10mM, pH 7.2) and monocytes were harvested from PBMCs using Milentyi CD14 magnetic beads. Viability was routinely $>98 \%$, as assessed by trypan blue exclusion. Monocyte cells were resuspended in RPMI 1640 containing penicillin $(100 \mu \mathrm{g} / \mathrm{ml})$, streptomycin $(100 \mu \mathrm{g} / \mathrm{ml})$ 
and $10 \%$ FBS. Monocytes were incubated at $37^{\circ} \mathrm{C}$ in $5 \% \mathrm{CO}_{2}$ overnight prior to stimulation.

THP-1 and THP-1 XBlue NF-kB/AP-1 SEAP reporter cell lines were maintained in RPMI 1640 at $37^{\circ} \mathrm{C} 5 \% \mathrm{CO}_{2}$. THP-1 XBlue cells were maintained with the addition of Zeocin $(200 \mu \mathrm{g} / \mathrm{ml})$. HEK 293 (human embryonic kidney) cells were maintained in DMEM with the addition of $10 \%$ FBS. HEK TLR 2/1, 2/6, 5 and null cells were maintained with blasticidin $(100 \mu \mathrm{g} / \mathrm{ml})$ and Normocin $(10 \mu \mathrm{g} / \mathrm{ml})$, whileTLR4-MD2CD14 cells were maintained with blasticidin $(100 \mu \mathrm{g} / \mathrm{ml})$, Normocin $(10 \mu \mathrm{g} / \mathrm{ml})$ and HygroGold $(50 \mu \mathrm{g} / \mathrm{ml})$. The TIGK (telomerase immortalized gingival keratinocytes) cell line was a kind gift from Dr. Richard Lamont (University of Louisville). TIGKs were maintained at $37^{\circ} \mathrm{C} 5 \% \mathrm{CO}_{2}$ in basal media.

\section{Production and purification of RagB}

P. gingivalis W83 genomic DNA was purified using Promega Isolation kits and the ragB gene was amplified by PCR (Fwd: CACCGAGCTTGACCGCGACCCC; Rev:

TATCGGCCAGTTCTTTATTAACTGCGG). The $\operatorname{rag} B$ product was gel purified on a $1 \%$ agarose gel and transformed into E.coli TOP10 strain using the pBAD202D TOPO vector and TOPO expression kit, according to manufacturer's instructions.

Transformants were plated on LB agar plates containing $50 \mu \mathrm{g} / \mathrm{ml}$ of kanamycin. PCR was used to confirm uptake of $\operatorname{rag} B$ in selected colonies. E.coli containing $\operatorname{rag} B$ were grown in LB broth and RagB expression was induced by arabinose. Cells were then pelleted and lysed using CellLytic B buffer. The recombinant his-tagged RagB was 
collected by column purification (300nM imidazole fraction; HiTrap Chelating HP column) and dialyzed using a Thermo Slide-A-Lyzer Cassette 10000 MWCO in PBS. The dialyzed product was checked for purity by both SDS-PAGE gel (Figure 3) and mass spectrometry, performed at the Mass Spectrometry Core Laboratory (University of Louisville, KY). Lack of biologically meaningful protein contamination and other pyrogens was confirmed by analysis of cytokine release from monocytes exposed to denatured (SDS-treated) and heat-treated (boiled) RagB preparations (Figure 4).

\section{RagB stimulation of IL-8 and NFאB in THP-1 cells}

THP-1 cell lines were maintained in buffered RPMI 1640. The THP-1 and THP-1 XBlue cell lines were plated in 96 well plates at $\sim 500,000$ cells per well. Cells were stimulated with $\operatorname{RagB}(0,1$, and $10 \mu \mathrm{g} / \mathrm{ml})$ and cell-free supernatant were harvested $\sim 20$ hour post stimulation. THP-1 supernatant was use to analyze IL-8 production by ELISA (eBioscience). THP-1 XBlue supernatant was used to measure NFkB production by the use of Quanti-Blue assays (measured at 595nm wave length). THP-1 XBlue cells contain a NFkB/AP-1 inducible reporter system which is used with Quanti-Blue assays to measure NFאB/AP-1 activation via secreted embryonic alkaline phosphatase (SEAP) reporter gene. E.coli LPS was used as a positive control for IL-8 and NFאB production.

\section{RagB stimulation of cytokines from TLR-transfected HEK-293 cells}

HEK cells were grown to $\sim 80 \%$ confluence in 96 tissue culture plates. HEK transfected hTLR2/1, 2/6, 4 and 5 cell lines were stimulated with their respective agonist 
(Pam3CSK4, FSL1, LPS and FLA-ST) and RagB ( $1 \mu \mathrm{g} / \mathrm{ml})$. HEK null cells were used as a negative control and stimulated with each TLR agonist and RagB, but did not induce IL-8 production. Cell-free supernatants were collected 20 hours post stimulation. IL-8 production was measured by ELISA.

\section{Quantification of RagB-induced cytokines in primary human monocytes}

Isolated monocytes were plated in 96 well plates at 300,000 cells/well. Cells were allowed to rest overnight at $37^{\circ} \mathrm{C}$ in $5 \% \mathrm{CO}_{2}$ and then stimulated with $\operatorname{Rag} \mathrm{B}(0.1,1$ or 10 $\mu \mathrm{g} / \mathrm{ml})$ or E.coli LPS (0.1 and $1 \mu \mathrm{g} / \mathrm{ml})$. Cell free supernatants were harvested following centrifugation $20 \mathrm{~h}$ post stimulation. ELISAs were used to measure IL-8, IL-6, IL-4, IL12, IL-10, IFN $\gamma$ and TNF concentrations in the supernatants.

\section{Identification of genes activated by RagB in a qRT-PCR TLR array}

Primary human monocytes were stimulated with RagB $(1 \mu \mathrm{g} / \mathrm{ml})$ for four hours. RNA was harvested with the 5-Prime RNA purification kit. cDNA was synthesized using qScript cDNA synthesis kit and then run on a thermal cycler under the following conditions: $22^{\circ} \mathrm{C}$ for $5 \mathrm{mins}, 42^{\circ} \mathrm{C}$ for $30 \mathrm{mins}, 85^{\circ} \mathrm{C}$ for 5 mins. One tenth of the firststrand reaction was used for the 96 well TLR Focused RT-PCR array plate, which allows for analysis of message derived from 84 genes in the human TLR pathway. SYBR® Green with ROX master mix was used as the fluorescence dye. An ABI 7500 RT-PCR machine was used to read the plate. Each plate contained 5 housekeeping controls and 
the RagB stimulated plate was compared with the unstimulated control plate. $2^{-\Delta \Delta C t}$ value was calculated.

\section{Identification of genes activated by RagB in primary human monocytes by whole} genome arrays

Whole genome microarrays were used to determine the transcriptomic response of primary human monocytes to RagB. Cells were plated in triplicate on 6 well plates at $4 \times 10^{6}$ cells/well. Cells were stimulated with 0,1 , or $10 \mu \mathrm{g} / \mathrm{ml}$ of RagB. RNA was harvested by 5-Prime RNA isolation kit four hours post stimulation. Total RNA (100 ng) was used per array. Following the manufacturer's protocol: RNA was used to synthesize first-strand cDNA (2hr incubation) and then synthesized to second-strand cDNA (1hr incubation). In vitro transcription of aRNA (amplified RNA) that was biotin labeled with an incubation period of $1 \mathrm{hr}$ at $16^{\circ} \mathrm{C}$ and $10 \mathrm{mins}$ at $60^{\circ} \mathrm{C}$. aRNA was purified to remove any salts or remaining free nucleotides. aRNA was then fragmented and incubated at $94^{\circ} \mathrm{C}$ for 35 mins. The fragmented product was hybridized to the GeneChip 3' arrays. Arrays were scanned using Command Console 3.2 (Affymetrix, St. Clara, CA). Each group was measured in triplicate and the averages were taken. Files were imported into Genomics Suite 6.6 (Partek Inc., St. Louis, MO) for summarization and background FDR correction. One way ANOVA was used to compare the different treatments. Ingenuity IPA software (Redwood City, CA) was used to filter genes with \pm 2 fold change, dosedependent response $(10>1>0 \mu \mathrm{g} / \mathrm{ml} \mathrm{RagB})$ and $\mathrm{P}$ value $<0.001 .243$ differentially

regulated genes were identified. Ingenuity software was used to look at gene clusters and 
potential pathways. Microarrays were analyzed at the University of Louisville Genomics Core facility.

\section{qRT-PCR validation of RagB-regulated genes}

Primary human monocytes were stimulated with 0 or $1 \mu \mathrm{g} / \mathrm{ml}$ of RagB. RNA was harvested using the 5-Prime RNA purification kit four hours post stimulation. RNA concentrations were measured by Nanodrop. cDNA was synthesized by qScript cDNA synthesis kit (Quanta). RT-PCR cycle conditions were as follows: 2 mins at $50^{\circ} \mathrm{C} ; 10$ mins at $95^{\circ} \mathrm{C} ; 15 \mathrm{sec}$ at $95^{\circ} \mathrm{C}, 1 \mathrm{~min}$ at $55^{\circ} \mathrm{C}$ for 40 cycles. An ABI-7500 RT-PCR machine was used to run the samples. Primer sequences (Table 1) were designed using Primer-BLAST (www.nchi.nlm.nih.gov/tools/primer-blast).

\begin{tabular}{|l|l|l|}
\hline Genes & Forward Primer & Reverse Primer \\
\hline IL-6 & TGCAATAACCACCCCTGACC & GTGCCCATGCTACATTTGCC \\
\hline IL-1 $\boldsymbol{\alpha}$ & CAGGAGCTTGTCACCCCAAA & CATGGAGTGGGCCATAGCTT \\
\hline CCL20 & CAGTGCTGCTACTCCACCTC & TTGGACAAGTCCAGTGAGGC \\
\hline IL-1 $\boldsymbol{\beta}$ & CGCTCCGGGACTCACAGCAA & GGTCCCTCCCAGGAAGACGGG \\
\hline IL-12 $\boldsymbol{\beta}$ & TCAAACCTGACCCACCCAAG & TCAGAACCTAACTGCAGGGC \\
\hline IL-8 & AGTCCTTGTTCCACTGTGCC & CACAGCACTACCAACACAGC \\
\hline STAT-4 & ATAAGAGGGAAGAGGACGCC & ACATGCTAGCGCTCTCTCAG \\
\hline RagB & CACCGAGCTTGACCGCGACCCC & TATCGGCCAGTTCTTTATTAACTGCGG \\
\hline GAPDH & GCCGCATCTTCTTTTGCGTC & TCGCCCCACTTGATTTTGGA \\
\hline
\end{tabular}

\section{Table 1. Primer sequences.}

Primers used to verify select RagB-regulated monocyte genes identified by microarray and to clone RagB. 


\section{TLR specificity of RagB in primary human monocytes}

Monocytes were plated in 96 well plates (300,000 cells/well) and allowed to rest overnight. Monocytes were pre-treated for one hour with $1 \mu \mathrm{g} / \mathrm{ml}$ of anti-TLR2 or -4 blocking antibodies. Cells were then stimulated with RagB $(1 \mu \mathrm{g} / \mathrm{ml})$ and the TLR2 and -4 agonists (HKLM at $10^{8}$ cells/ml and LPS-EK at $\left.1 \mu \mathrm{g} / \mathrm{ml}\right)$. Cell free supernatants were harvested 20 hours post stimulation. ELISA was used to measure cytokine production.

\section{Inhibition of STAT4 in RagB-stimulated primary human monocytes}

Primary human monocytes were pre-treated with the STAT4 inhibitor, lisofylline (LSF), for one hour. Cells were then stimulated with RagB $(1 \mu \mathrm{g} / \mathrm{ml})$ and cell-free supernatants were harvested 20 hours post stimulation. Cytokine production was measured by ELISA.

\section{Inhibition of NFкB (p65) in RagB-stimulated primary human monocytes}

Primary human monocytes at 300,000 cells/well in 96 well plates were untreated or exposed to combinations of $\operatorname{RagB}(1 \mu \mathrm{g} / \mathrm{ml})$ or $E$. coli LPS $(1 \mu \mathrm{g} / \mathrm{ml})$ and a p65 or negative control peptide inhibitor set $(100 \mu \mathrm{M}, 1 \mathrm{hr}$ pre-treatment). Cell free supernatants were harvested 20 hours post stimulation. Cytokine production was measured by ELISA. 


\section{TLR2, TLR4, p65 and STAT4 gene silencing}

TLR2, TLR4, p65 and STAT4 genes were individually silenced in human monocytes by siRNA transfection using the 4D-Nucleofactor system, according to the manufacturer's P3 primary cell protocol. A control siRNA scrambled sequence was used as a negative control. Briefly, $\sim 4$ million cells were suspended in $100 \mu 1$ transfection reagent in single nucleocuvettes and $3 \mu \mathrm{l}(30 \mathrm{pM})$ of siRNA added. Transfected monocytes were rested in RPMI 1640 containing $10 \% \mathrm{FBS}$ for $48 \mathrm{~h}$ at $37^{\circ} \mathrm{C}$ prior to stimulation with $\mathrm{RagB}$ and other agonists, as described in the figure legends (9-12). Confirmation of gene silencing was performed by Western blot analysis as shown in Figures 9, 11-12.

\section{Colonization of epithelial cells by wildtype and $\triangle \operatorname{rag} B P$. gingivalis strains}

TIGK cells were used as a model to study bacterial interactions with gingival epithelial cells. TIGKs were plated in 12 well plates or 4-chambered glass slides until $80 \%$ confluence was attained. TIGKs were maintained in basal media. $P$. gingivalis strains (W83, $\operatorname{rag} B$, and complement) were used to infect the TIGKs at MOI of 10:1 for one hour. Cells were then washed with PBS and basal media containing gentamicin (300 $\mu \mathrm{g} / \mathrm{ml})$ and metronidazole $(200 \mu \mathrm{g} / \mathrm{ml})$ was added for one hour. TIGK cells were then lysed and lysates plated on GAM/blood agar or fixed with paraformaldehyde for confocal analysis. CFUs were enumerated after seven days of anaerobic incubation. Unexposed TIGKs were used as a negative control. Paraformaldehyde $4 \%$ was added to the chambered wells for 20 minutes. Cells were washed with PBS and 0.2\% Triton X-100 
was added for 10 mins. Wells were washed with PBS, and $10 \%$ horse serum was added for 20 mins. Primary anti-P. gingivalis antibodies were added at 1:1000 for one hour. Wells were then washed with PBS and the secondary antibody (anti-rabbit; 1:200) was added for one hour. Wells were washed with PBS and phalloidin-TRITC (1:100) was added for 40 minutes. Wells were then washed with PBS and coverslips were mounted using Prolong Gold with DAPI and allowed to cure overnight. Slides were viewed using Fluoview FV1000 confocal system at 60X magnification.

\section{Induction of cytokines by wildtype and $\triangle \operatorname{rag} B \boldsymbol{P}$. gingivalis in monocytes}

Bacterial strains W83, $\operatorname{rag} B$, and complement were harvested at late log phase. Cells were washed with PBS and fixed in $1 \%$ paraformaldehyde for one hour. Bacterial cells were fixed prior to cell stimulation to control for the degradation of cytokines by bacterial proteases. After fixation, cells were washed in PBS and used to stimulate primary monocytes at a MOI of 10:1. Cell free supernatants were collected 20 hours post stimulation for analysis by ELISA.

\section{Preparation of RagB for crystallization}

Purified RagB was digested with 0.1 unit of EKMax per $20 \mu \mathrm{g}$ of protein. The reaction mixture contained RagB, 10X EKMax Buffer and 0.1 unit of EKMax. The mixture was incubated at $37^{\circ} \mathrm{C}$ for 16 hours. EKMax was removed using EK-Away resin. Briefly, EK-Away resin was added to the mixture for two minutes and then pelleted. The 
supernatant was removed and the pellet resuspended in EK-Away Resin for another two minutes. EK-Away $1 \mathrm{X}$ buffer was added and EK-Away Binding buffer was added to the Enterokinase digestion mixture for 15 minutes and centrifuged. The supernatant was run on SDS-PAGE gel and stained with Coomassie Blue to verify the correct size. Products were then concentrated and sent for crystallization. Pymol generated the image, and the analysis is currently being performed by our collaborator, Dr. Theodoros Goulas (Structural Biology, Molecular Biology Institue of Barcelona, Spain).

\section{Statistical analysis}

All experiments were performed in triplicate unless otherwise stated. Data were analyzed by student $t$-test or one-way ANOVA using GraphPad and Prism 4 software. $P$ value less than or equal to 0.05 was considered to represent statistically significant differences between groups. 


\section{CHAPTER THREE: RESULTS}

\section{RagB production and purification}

Purified, recombinant RagB protein was shown to be free of contaminants first by using a NuPAGE gel stained with both Coomassie Blue and silver staining techniques (Figure 3). Subsequently, the RagB band was extracted and sequenced using mass spectrometry to confirm the presence of a single amino acid sequence homologous to that expected for RagB. Primary human monocytes were used to test denatured RagB for possible LPS, or other pyrogen, contamination by heat-denaturing the protein at $80^{\circ} \mathrm{C}$ for 20 mins or treating the protein with $10 \%$ SDS prior to stimulation. Heat-denatured and SDS treated RagB did not elicit an IL-8 response in monocytes (Figure 4), further verifying the recombinant protein to be free of contamination. IL- 8 is a pro-inflammatory cytokine that is involved in neutrophil recruitment and its promoter contains both an NFKB and AP1 binding site that is inducible by LPS [97]. 


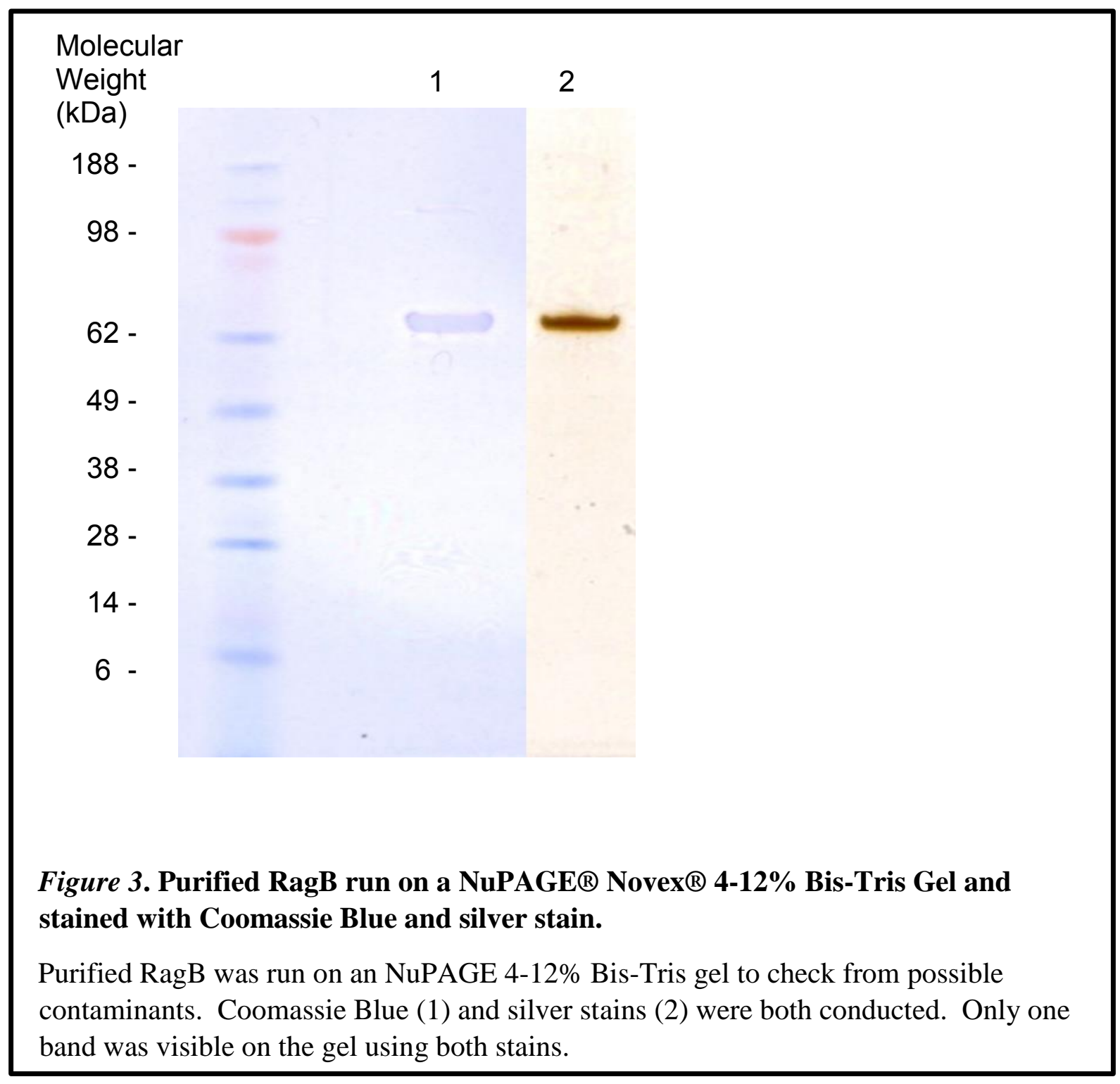




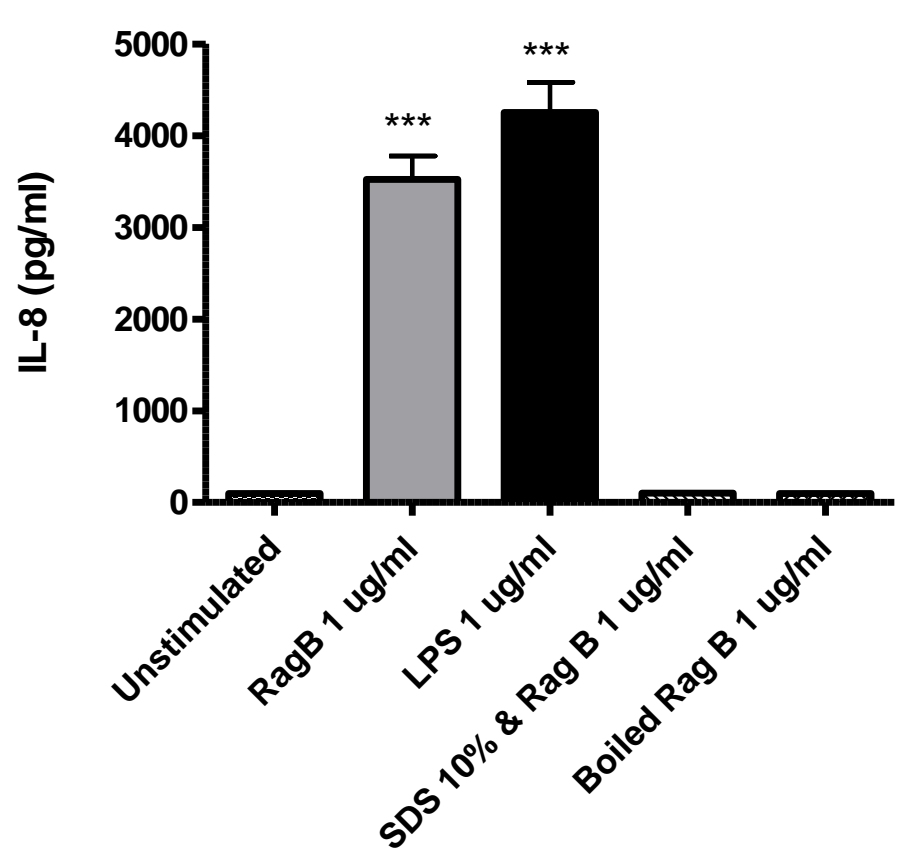

Figure 4. Denatured RagB does not elicit a IL-8 response.

Monocytes were stimulated with RagB ( $1 \mu \mathrm{g} / \mathrm{ml})$, LPS $(1 \mu \mathrm{g} / \mathrm{ml})$, SDS treated RagB or boiled RagB. Cell free supernatants were harvested at $20 \mathrm{hrs}$ post stimulation and IL-8 quantified by ELISA.

*** $\mathrm{p}<0.001$ compared to the unstimulated control

\section{RagB does not elicit a response in THP-1 and HEK transfected cell lines}

Monocytic whole genome array data suggested that RagB induced multiple genes known to be regulated by the transcription factor NFkB. THP-1 cells are monocytic leukemic cells commonly used to study innate immunity while THP-1XBlue cells contain a reporter plasmid controlled by an NFKB promoter system. Therefore, THP-1 cells were challenged with RagB and E.coli LPS was used as a positive control for IL-8 cytokine production. Cell free supernatants were harvested at 20 hours post stimulation. ELISA used to measure the concentration of IL-8 in supernatants. RagB did not induce an IL-8 response in the THP-1 cell line (Figure 5). 
THP-1 XBlue cells were then used to determine if NFאB could be activated by RagB. Quanti-Blue assays were performed on $20 \mathrm{~h}$ cell free supernatants in order to

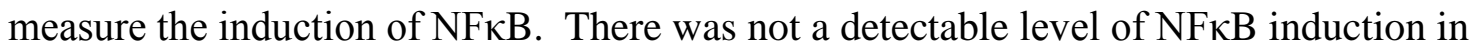
THP-1 XBlue cells by RagB as shown in Figure 6. E.coli LPS was used as a positive control for NFKB induction.

HEK cells are commonly used to identify TLR agonists since they are readily transfected and do not naturally express surface TLRs. HEK hTLR cells stably transfected with TLR-2/-1, TLR-2/-6, TLR-4, and TLR-5, as well as null transfected HEK control cells were used to measure RagB induction of IL-8. Cells were unstimulated or stimulated with $\operatorname{RagB}(1 \mu \mathrm{g} / \mathrm{ml})$ or their respective classical agonists (2/1, Pam3CSK4 at $1 \mu \mathrm{g} / \mathrm{ml} ; 2 / 6$, FSL1 at $1 \mu \mathrm{g} / \mathrm{ml} ; 4$, LPS at $1 \mu \mathrm{g} / \mathrm{ml} ; 5$, FLA-ST at 1 $\mu \mathrm{g} / \mathrm{ml})$. Cell free supernatants were collected 20 hours post stimulation. IL-8 cytokine production was measured by ELISA. RagB induction of IL-8 was not detected in any of the surface TLR transfected HEK cell lines, as shown in Figure 7. 


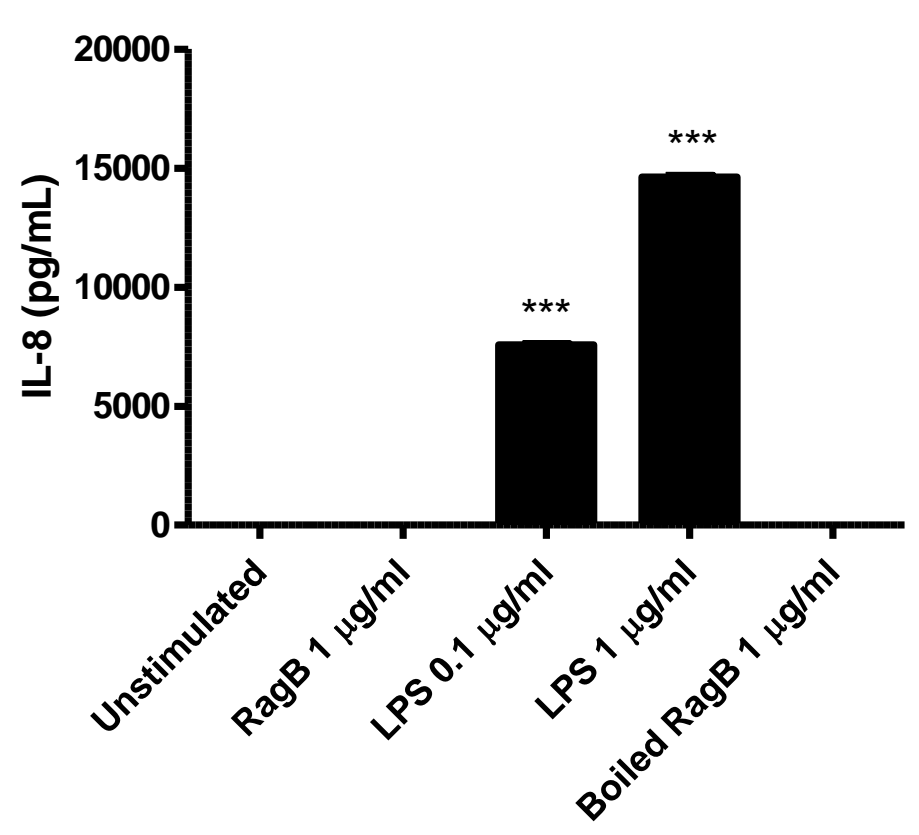

Figure 5. RagB does not induce an IL-8 response in THP-1 cells.

THP-1 cells were stimulated with $\operatorname{RagB}(1 \mu \mathrm{g} / \mathrm{ml})$, LPS $(0.1$ and $1 \mu \mathrm{g} / \mathrm{ml})$, and boiled RagB. Cell free supernatants were harvested at $20 \mathrm{hrs}$ post stimulation for ELISA. *** $\boldsymbol{p}<0.001$ compared to unstimulated control. 


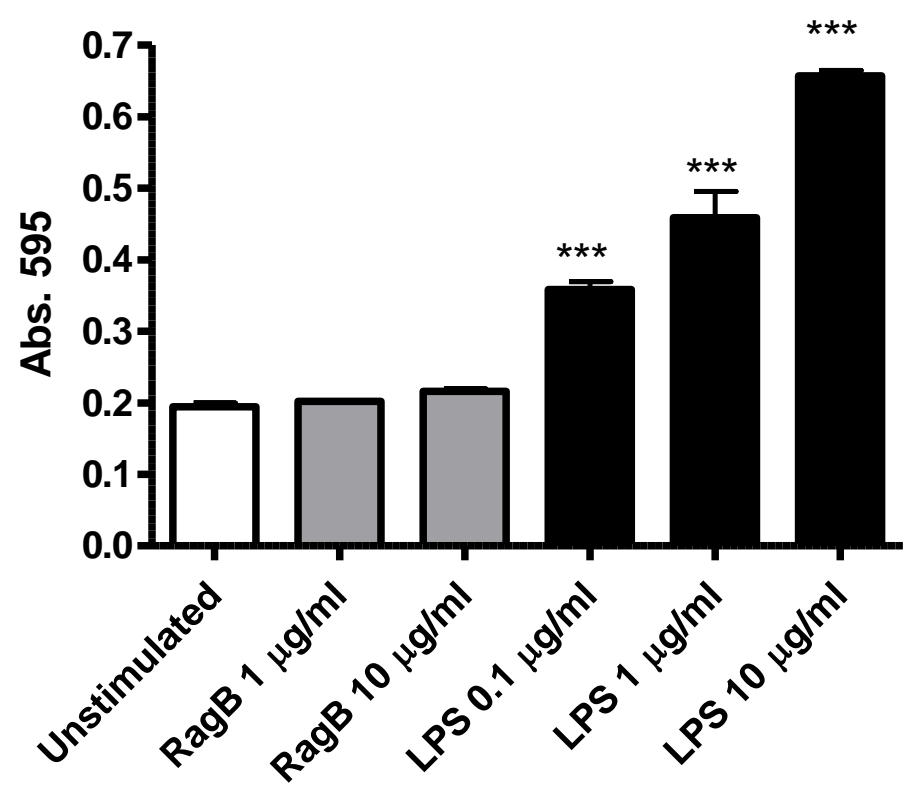

Figure 6. RagB does not induce NFKB in THP-1 XBlue cell line.

THP-1 XBlue cells were stimulated with RagB (1 and $10 \mu \mathrm{g} / \mathrm{ml})$, LPS $(0.1,1$ and 10 $\mu \mathrm{g} / \mathrm{ml})$. Cell free supernatant was harvested $20 \mathrm{hrs}$ post stimulation. Quanti-Blue assays were used to measure induction of $\mathrm{NF} \kappa \mathrm{B}$ by secreted alkaline embryonic phosphatase. *** $\boldsymbol{p}<0.001$ compared to unstimulated control. 
A

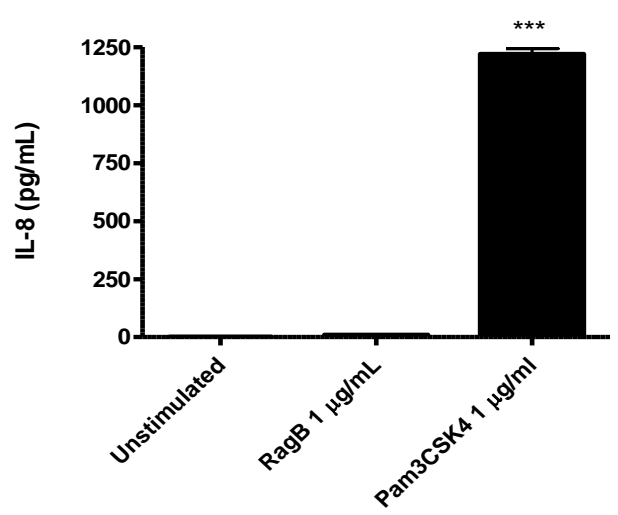

C

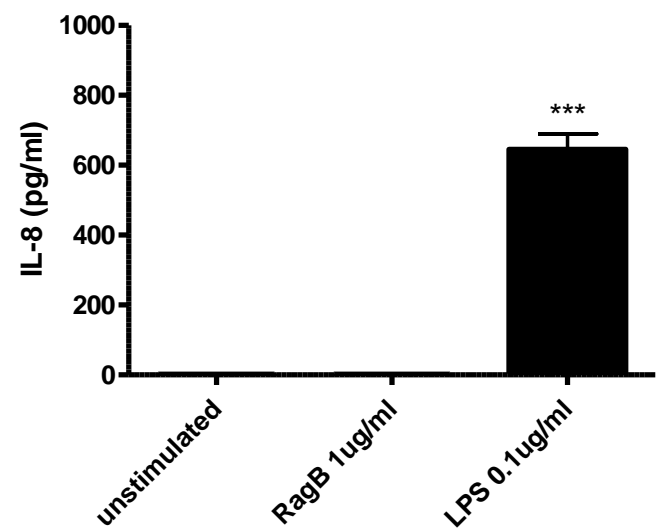

B

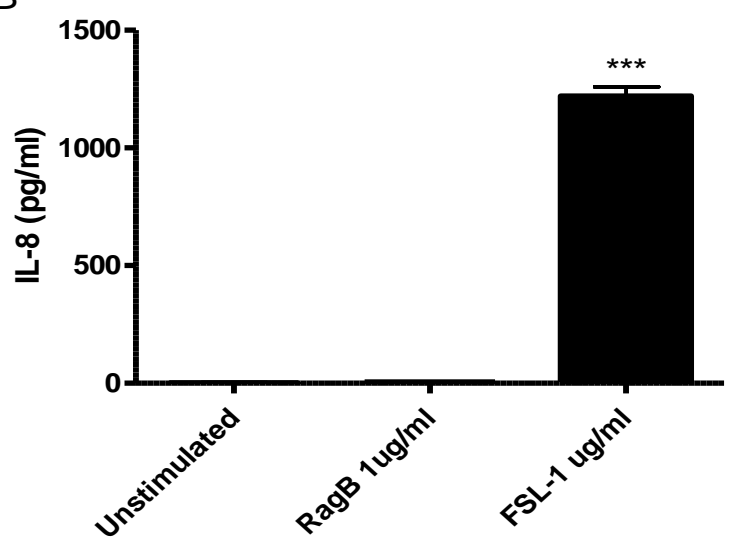

D

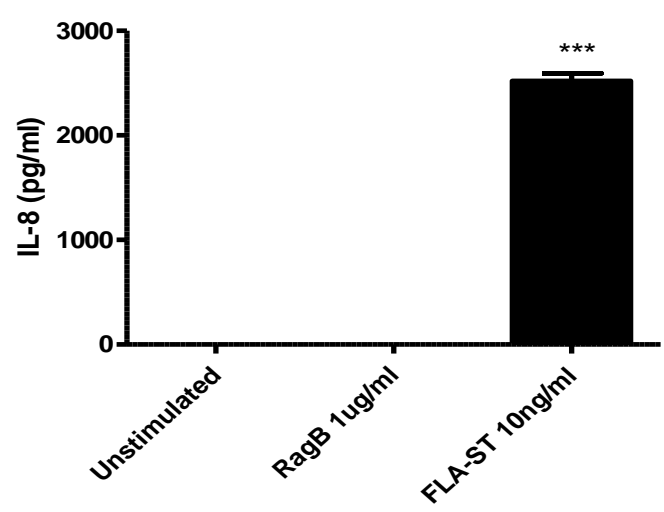

Figure 7. RagB does not signal through surface exposed TLRs in HEK cell lines.

HEK 293 cells transfected with (A) hTLR 2/1, (B) hTLR 2/6, (C) hTLR 4 and (D) hTLR 5. Cells were stimulated with $\operatorname{RagB}(1 \mu \mathrm{g} / \mathrm{ml})$ and TLR respective agonist. Cell free supernatant was harvested $20 \mathrm{hrs}$ post stimulation and measured by ELISA.

$* * * \boldsymbol{p}<0.001$ compared to unstimulated control. 


\section{RagB induces pro-inflammatory cytokines in primary human monocytes}

To measure cytokine levels, primary monocytes were stimulated with RagB $(0.1$, 1 or $10 \mu \mathrm{g} / \mathrm{ml})$ and E.coli LPS $(0.1$ or $1 \mu \mathrm{g} / \mathrm{ml})$ for 20 hours. Cell free supernatant was harvested for ELISA. RagB induced a significant, dose-related increase in the IL-8 response, compared to unstimulated controls (Figure 8). Similar results were obtained for both IL-6 and TNF (Figure 8). This confirms RagB promotes production of proinflammatory cytokines in primary human monocytes. RagB was also degraded by boiling and SDS digestion. Cells stimulated with degraded RagB did not induce an inflammatory response (Figure 4). 


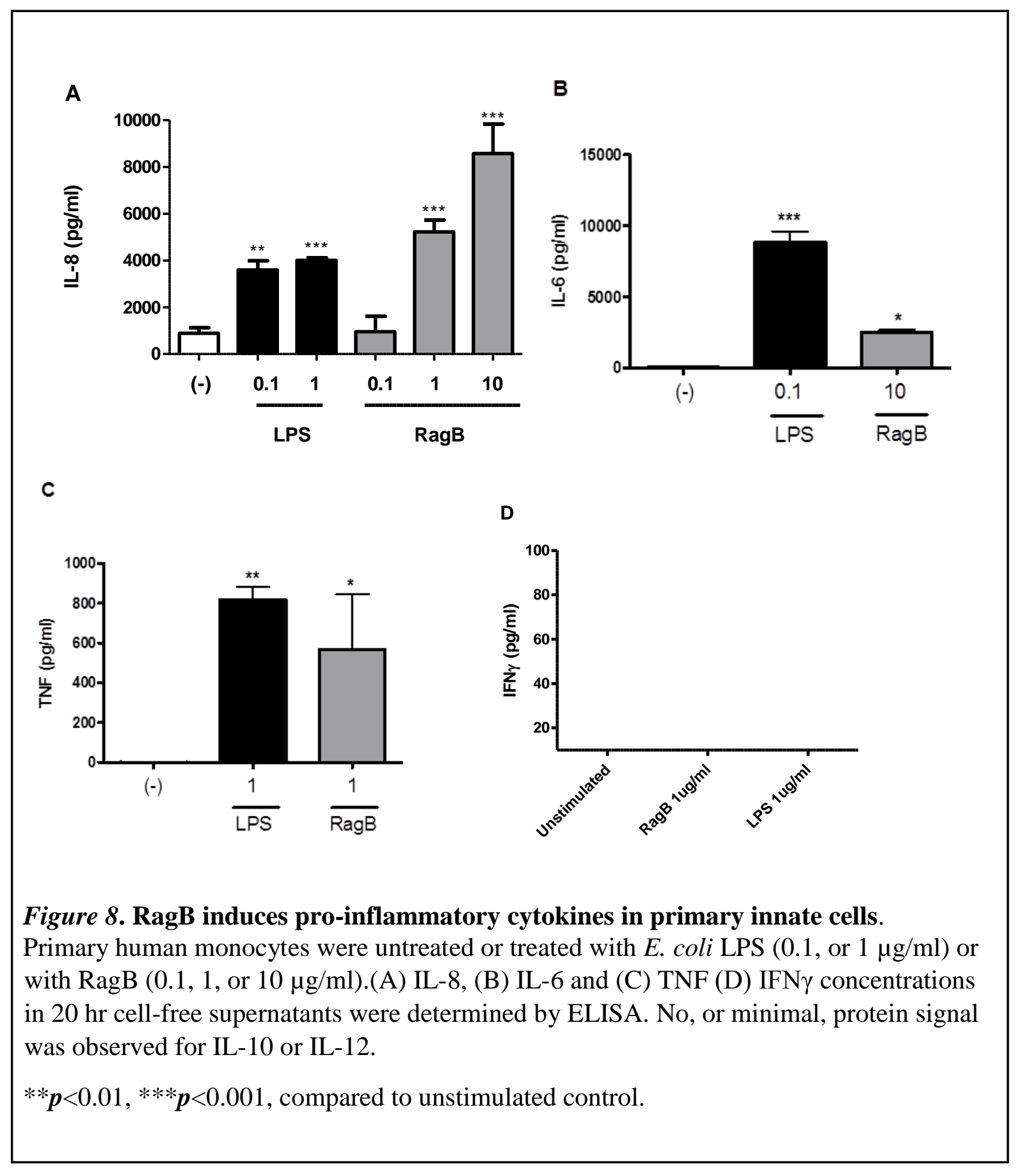




\section{RagB induces multiple pro-inflammatory genes in TLR-focused arrays}

In order to understand the mechanisms of pro-inflammatory cytokine induction by RegB, we initially used focused arrays to screen for RagB activation of 84 major TLR pathway-related genes. Primary human monocytes were stimulated with 0 or $1 \mu \mathrm{g} / \mathrm{ml}$ RagB and total RNA was harvested four hours post stimulation. Additionally, LPS 1 $\mu \mathrm{g} / \mathrm{ml}$ was used as a positive control. cDNA was synthesized and used in RT-PCRbased, TLR-focused arrays. Each set of TLR genes were compared to 5 housekeeping genes and the $2^{-\Delta \Delta c t}$ method [98] was used to compare unstimulated vs stimulated groups. The pro-inflammatory genes encoding IL-1 $\beta$, IL-8, IL-1 $\alpha$, CCL2, and IL-6 were each shown to be upregulated in cells stimulated with $\operatorname{RagB}$ as shown in Table 2. The genes CCL2, CLEC4E, HSPA1A, IL-1 $\alpha$, IL-8, NFkB1A, PTGS2 and REL were shown to be upregulated in cells stimulated with LPS as shown in Table 3. 


\begin{tabular}{|c|c|c|}
\hline Gene & Description & Fold change \\
\hline IL-1 $\beta$ & Interleukin 1, beta & 83.4 \\
\hline IL-8 & Interleukin 8 & 35.3 \\
\hline IL-1 $\alpha$ & Interleukin 1, alpha & 18.7 \\
\hline CCL2 & Chemokine (C-C motif) ligand 2 & 7.1 \\
\hline IL-6 & Interleukin 6 & 5.8 \\
\hline
\end{tabular}

Table 2. RagB induces multiple TLR-related genes in primary human monocytes. RNA was harvested $4 \mathrm{hr}$ post treatment and reverse transcribed for hTLR RT-PCR array. The $2^{-\Delta \Delta c t}$ method was used to determine significant differences from the control (unstimulated) group. 5 of the 84 genes in the TLR Signaling Pathway RT² Profiler PCR array were upregulated, as noted above.

\begin{tabular}{|c|c|c|}
\hline \multicolumn{2}{|c|}{ Description } & Fold Change \\
\hline CCL2 & Chemokine (C-C motif) ligand 2 & 14.0 \\
\hline CLEC4E & Colony stimulating factor 2 (granulocyte-macrophage) & 19.1 \\
\hline HSPA1A & Heat shock 70kDa protein 1A & 2.6 \\
\hline IL-1 $\alpha$ & Interleukin 1, alpha & 80.2 \\
\hline IL-8 & Interleukin 8 & 196.2 \\
\hline NFKBI $\alpha$ & Nuclear factor of Kappa light polypeptide gene chancer in B-cells & 19.4 \\
\hline PTGS2 & Prostaglandin-endoperoxide synthase 2 & 290.0 \\
\hline REL & V-rel reticuloendotheliosis viral oncogene homolog & 17.6 \\
\hline
\end{tabular}

Table 3. LPS induces multiple TLR-related genes in primary human monocytes. RNA was harvested $4 \mathrm{hr}$ post treatment and reverse transcribed for hTLR RT-PCR array. The $2^{-\Delta \Delta c t}$ method was used to determine significant differences from the control (unstimulated) group. 8 of the 84 genes in the TLR Signaling Pathway RT² Profiler PCR array were upregulated, as noted above 


\section{RagB induces multiple pro-inflammatory genes in a dose-dependent manner in whole genomic microarrays}

Focused TLR arrays identified RagB-induced pro-inflammatory mediators, but did not provide any insights on the underlying mechanisms involved in cytokine induction. Therefore, we next determined the whole genomic response of primary human monocytes to RagB stimulation. Monocytes were stimulated with 0,1 or $10 \mu \mathrm{g} / \mathrm{ml}$ of RagB for four hours and total RNA was harvested. The results were filtered by Bonferroni correction and genes were considered differentially regulated if there was \pm 2 fold change in message level at each dosage when compared to the unstimulated control, and a dose-related response (i.e. the induced signal at $10 \mu \mathrm{g} / \mathrm{ml}$ was $>1 \mu \mathrm{g} / \mathrm{ml}$ which was $>0 \mu \mathrm{g} / \mathrm{ml}$ ) that was statistically significant $(\mathrm{p}<0.001)$. The filtered list contained 243 genes, of which selected upregulated genes are presented in Table 4. Genes selected are implemented in NFKB/STAT pathways suggesting a possible signaling mechanism of RagB-induction. These selected genes were verified by real-time PCR, again, as shown in Table 4. Similar results were obtained in the RT-PCR array (Table 2) for IL-6, IL-8 and IL-1 $\beta$. STAT4 was shown to be the most upregulated transcription regulator, coincidently, is connected to many of the most upregulated genes as shown in Figure 9. This suggests RagB promotes a strong pro-inflammatory signal that could activate transcription through the STAT4 pathway. 


\begin{tabular}{|l|l|l|l|}
\hline \multirow{2}{*}{ Gene } & \multicolumn{2}{l}{ Fold Change } & \multicolumn{2}{l|}{} \\
\cline { 2 - 4 } & \multicolumn{2}{|l|}{ Microarray } & RT-PCR \\
\cline { 2 - 4 } ILs0 & $\mathbf{1 0 v s 0}$ & $\mathbf{1 v s 0}$ \\
\hline CCL20 & 612 & 800 & 153 \\
\hline IL-1 $\beta$ & 295 & 449 & 34 \\
\hline IL-12 $\beta$ & 146 & 765 & 2.8 \\
\hline STAT4 & 35 & 51 & 6 \\
\hline TNF & 24 & 32 & 9 \\
\hline IL-8 & 7.3 & 7.5 & 2.7 \\
\hline
\end{tabular}

Table 4. RagB induces multiple pro-inflammatory genes in dose-related manner. Primary human monocytes were stimulated with 0,1 or $10 \mu \mathrm{g} / \mathrm{ml}$ of RagB. RNA was harvested $4 \mathrm{hr}$ post-stimulation and used for microarray analysis. 243 genes were differentially regulated, as determined by Bonferroni correct $\mathrm{p}$-value, and also exhibited a dose-related response $(10>1>0 \mu \mathrm{g} / \mathrm{ml} \mathrm{RagB})$. Selected genes were verified by RTPCR. RT-PCR was analyzed by $2^{-\Delta \Delta C t}$ method. 


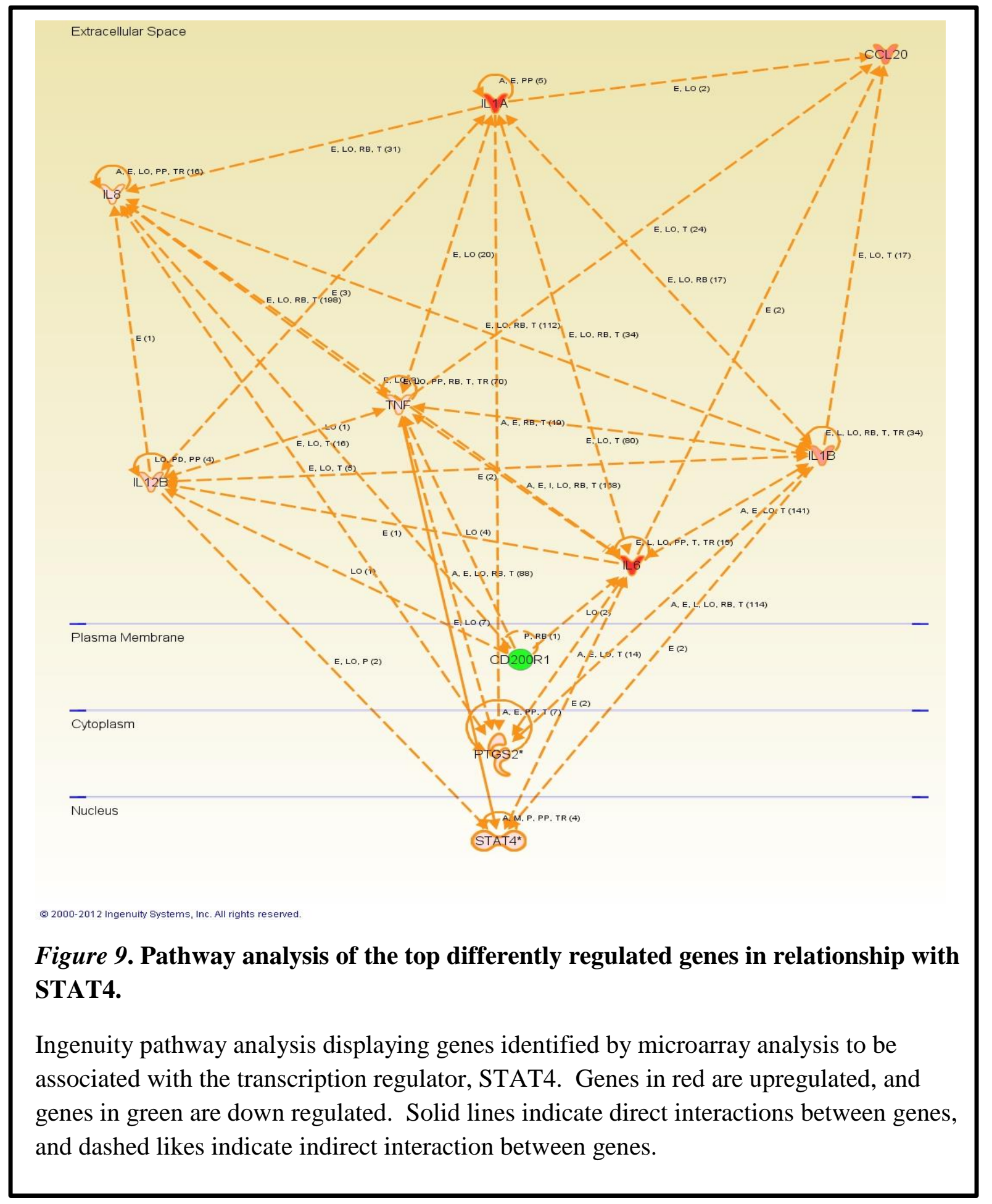




\section{RagB induction of IL-8 is TLR2-dependent}

Toll-like receptors (TLRs) play a major role in microbial recognition and innate immune signaling. Previous studies have shown TLRs to be essential in $P$. gingivalis induced infections $[65,99,100]$. TLR2 was shown to be required for $P$. gingivalis induced oral bone loss using TLR2-knockout mice[101]. To investigate the potential engagement of TLR-2 by RagB, anti-hTLR2 antibodies were used to block binding of TLR-2 agonists to primary human monocytes. Anti-TLR2 and IgA2 (isotype control) antibodies were added at $1 \mu \mathrm{g} / \mathrm{ml}$ for one hour prior to RagB stimulation. RagB (1 $\mu \mathrm{g} / \mathrm{ml}$ ) was used to stimulate the cells and cell free-supernatants were harvested 20 hours post stimulation. The classic TLR-2 agonist, Pam3CSK4, was used as a positive control. Cells exposed to anti-TLR2 antibodies then RagB showed a significant decrease in IL-8 production when compared with cells stimulated with RagB alone (Figure 10). IgA2 isotype control did not influence RagB-induced IL-8 production. This suggests RagB induces IL-8 production at least partially through TLR2.

To confirm TLR-2 engagement by RagB, a second experimental approach was adopted, i.e., gene silencing. Primary human monocytes were transfected with $30 \mathrm{pM}$ of control (non-targeting negative control) or TLR-2-specific siRNA. Cells were allowed to rest for 48 hours and then stimulated with $\operatorname{RagB}(1 \mu \mathrm{g} / \mathrm{ml})$ for 4 or 20 hours. Total protein was harvested at 4 hours post stimulation and cell free supernatant was harvested at 20 hours post stimulation. Successful TLR-2 silencing was confirmed by Western blot and the subsequent reduction of IL-8 induction upon RagB stimulation in silenced cells is shown in Figure 10. 

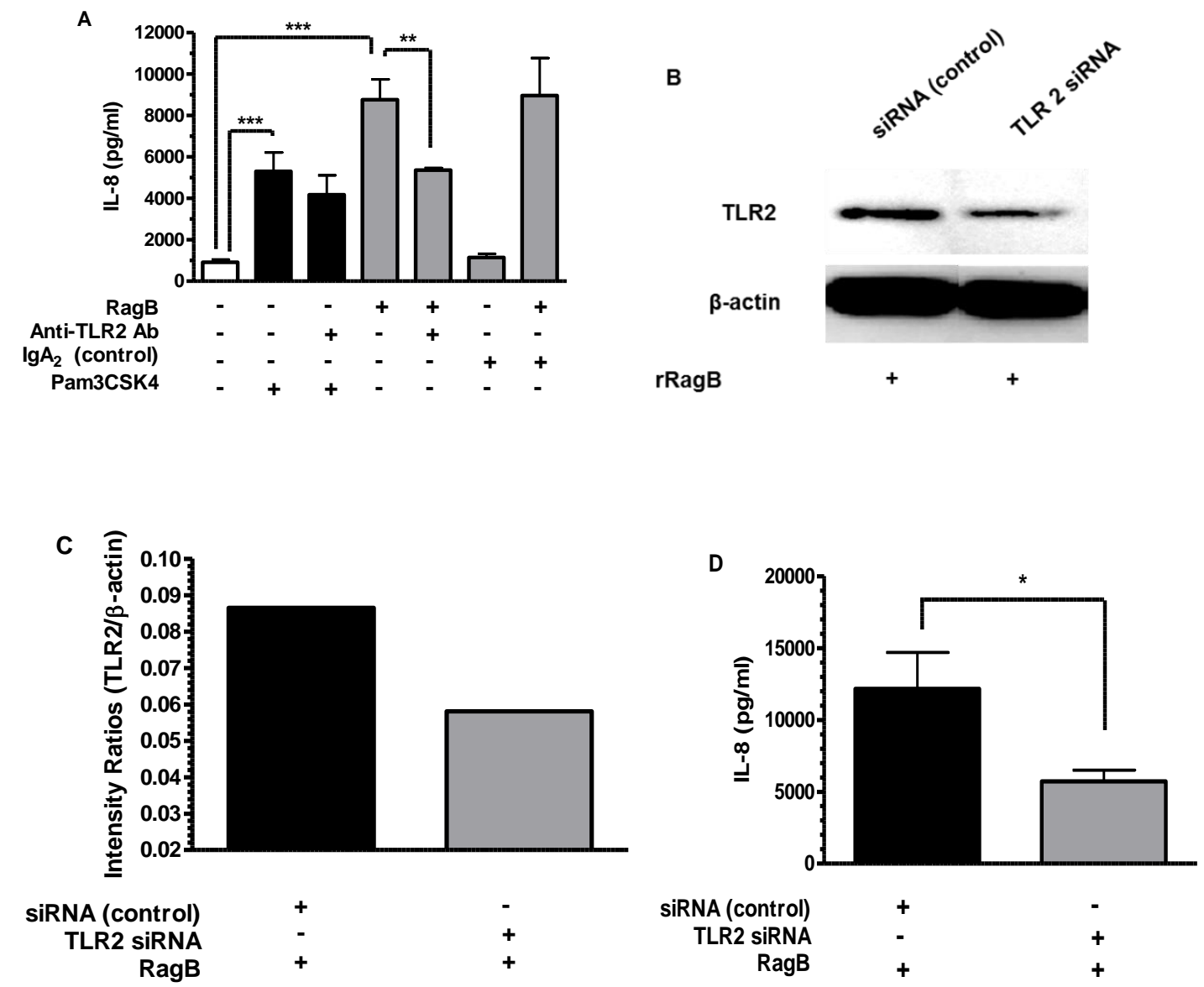

Figure 10. RagB induction of IL-8 is TLR2-dependent.

Primary human monocytes were untreated or exposed to combinations of RagB (1 $\mu \mathrm{g} / \mathrm{ml})$; the TLR2 agonist, Pam3CSK4 $(1 \mu \mathrm{g} / \mathrm{ml})$, anti-TLR2 $(1 \mu \mathrm{g} / \mathrm{ml}, 1 \mathrm{hr}$ pretreatment) and control (IgA2, $1 \mu \mathrm{g} / \mathrm{ml}, 1 \mathrm{hr}$ pre-treatment) antibodies. In an alternative strategy, TLR2 gene silencing was performed, as described in the text. (A) IL-8 concentrations in $20 \mathrm{hr}$ cell-free supernatants were determined by ELISA. TLR2 knockdown was confirmed by (B) Western blot and (C) densitometry. (D) Inhibition of RagB induced IL-8 upon TLR2 gene silencing was determined by ELISA. $* \boldsymbol{p}<0.05, * * \boldsymbol{p}<0.01, * * * \boldsymbol{p}<0.001$. (B) and (C) represent typical data. 


\section{RagB induction of IL-8 is TLR4-dependent}

To investigate the potential engagement of TLR4 in the innate response to RagB, anti-TLR4 antibodies were used to block TLR4 agonists to primary human monocytes. Anti-TLR4 and IgG1 (isotype control) antibodies were added at $1 \mu \mathrm{g} / \mathrm{ml}$ for one hour prior to RagB stimulation. The classic TLR4 agonist, LPS, was used as a positive control. Cells exposed to anti-TLR4 antibodies then RagB showed a significant decrease in IL-8 production when compared with cells stimulated with RagB alone (Figure 11) IgG1 isotype control did not influence RagB-induced IL-8 production. This suggests RagB induction of IL-8 is at least partially though TLR4.

We attempted to confirm TLR4 engagement by RagB using a second experimental approach, i.e., gene silencing, but were unsuccessful after multiple attempts. 


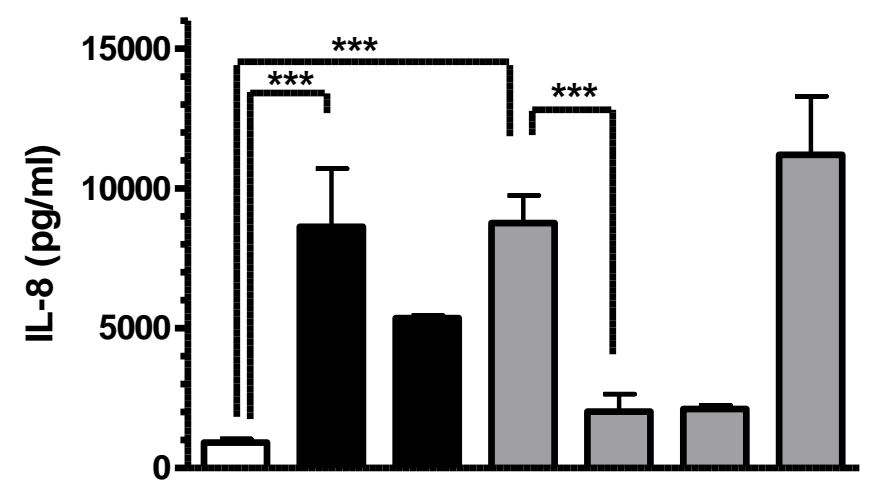

$\begin{array}{rccccccc}\text { RagB } & - & - & - & + & + & - & + \\ \text { Anti-TLR4 } & - & - & + & - & + & - & - \\ \operatorname{lgG}_{1}(\text { control) } & - & - & - & - & - & + & + \\ \text { LPS } & - & + & + & - & - & - & -\end{array}$

Figure 11. RagB induction of IL-8 is TLR4-dependent.

Primary human monocytes were untreated or exposed to combinations of RagB (1 $\mu \mathrm{g} / \mathrm{ml})$; the TLR4 agonist, LPS $(1 \mu \mathrm{g} / \mathrm{ml})$, anti-TLR4 $(1 \mu \mathrm{g} / \mathrm{ml}, 1 \mathrm{hr}$ pre- treatment $)$ and control (IgG1, $1 \mu \mathrm{g} / \mathrm{ml}, 1 \mathrm{hr}$ pre-treatment) antibodies. IL-8 concentrations in $20 \mathrm{hr}$ cellfree supernatants were determined by ELISA.

$* * * p<0.001$

\section{RagB induction of IL-8 is STAT4-dependent}

Genomic microrarrays identified STAT4 as a potentially important transcription regulator in the RagB-induced innate response. STAT4 has previously been shown to play a critical role in inflammation in monocytic cells [102]. Thus, the STAT4 inhibitor, LSF, was used to pharmaceutically inhibit STAT4 in cells stimulated with RagB.

Primary human monocytes were pre-treated with LSF (25 or $100 \mu \mathrm{M})$ for one hour. Cells were then stimulated with RagB $(1 \mu \mathrm{g} / \mathrm{ml})$. Cell free supernatants were harvested 20 hours post infection for detection of IL- 8 by ELISA. LSF significantly suppressed the induction of IL-8 by RagB. 
In addition to pharmaceutical inhibition of STAT4, gene silencing by siRNA was also used to investigate RagB signaling. Primary human monocytes were transfected with 30 pM of control or STAT4-specific siRNA. Cells were allowed to rest for 48 hours and then stimulated with $\operatorname{RagB}(1 \mu \mathrm{g} / \mathrm{ml})$ for 4 and 20 hours. Total protein was harvested at 4 hours post stimulation and cell free supernatant was harvested at 20 hours post stimulation. There was a decrease in total STAT4 protein at 4 hours and a significant decrease in IL-8 production in cells stimulated with RagB transfected with STAT4 siRNA (Figure 12). This strongly suggests RagB signals though STAT4 in the context of IL-8 induction. 


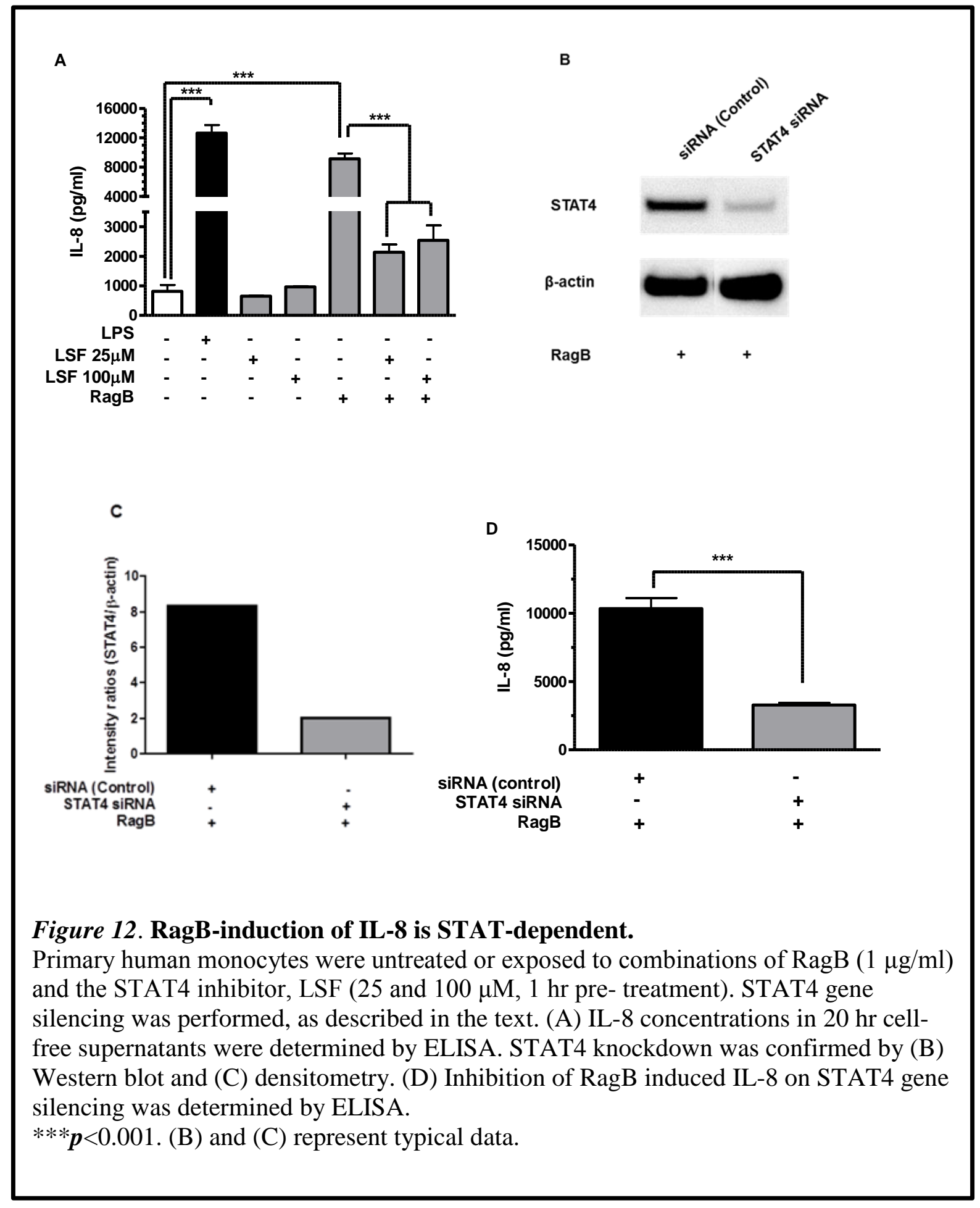




\section{RagB induction of IL-8 is NF-kB (p65)-dependent}

The NFkB transcriptional pathway is the best defined major pathway controlling pro-inflammatory responses to pathogens and MAMPs. An NFkB p65 (Ser276) inhibitor peptide was used to block phosphorylation of the NFאB complex in cells stimulated with RagB. The peptide inhibitor acts as a p65 decoy through the phosphorylation of the Ser276 site located on the peptide. Primary human monocytes were pre-treated with p65 or control peptide one hour prior to stimulation with RagB $(1 \mu \mathrm{g} / \mathrm{ml})$ or E.coli LPS (1 $\mu \mathrm{g} / \mathrm{ml}$ ). LPS is a typical TLR4 agonist thus was used as a positive control for NFKB induction. Cell free supernatants were harvested 20 hours post stimulation and their IL-8 content quantified by ELISA. The IL- 8 response in RagB stimulated monocytes was not influenced by a negative control peptide. The p65 peptide inhibitor, on the other hand, significantly suppressed the induction of IL-8 by RagB.

Again, a gene silencing approach was taken in order to confirm the importance of p65 in the inflammatory response of primary innate cells to RagB. Primary human monocytes were transfected with $30 \mathrm{pM}$ of control or p65-specific siRNA. Cells were allowed to rest for 48 hours and then stimulated with RagB $(1 \mu \mathrm{g} / \mathrm{ml})$ for 4 or 20 hours. Total protein was harvested at 4 hours post stimulation and cell free supernatant was harvested at 20 hours post stimulation. There was a decrease in total p65 protein at 4 hours and a significant decrease in IL-8 production in cells stimulated with RagB transfected with p65 siRNA (Figure 13). This strongly suggests RagB signals though NFKB in the context of IL-8 induction. 


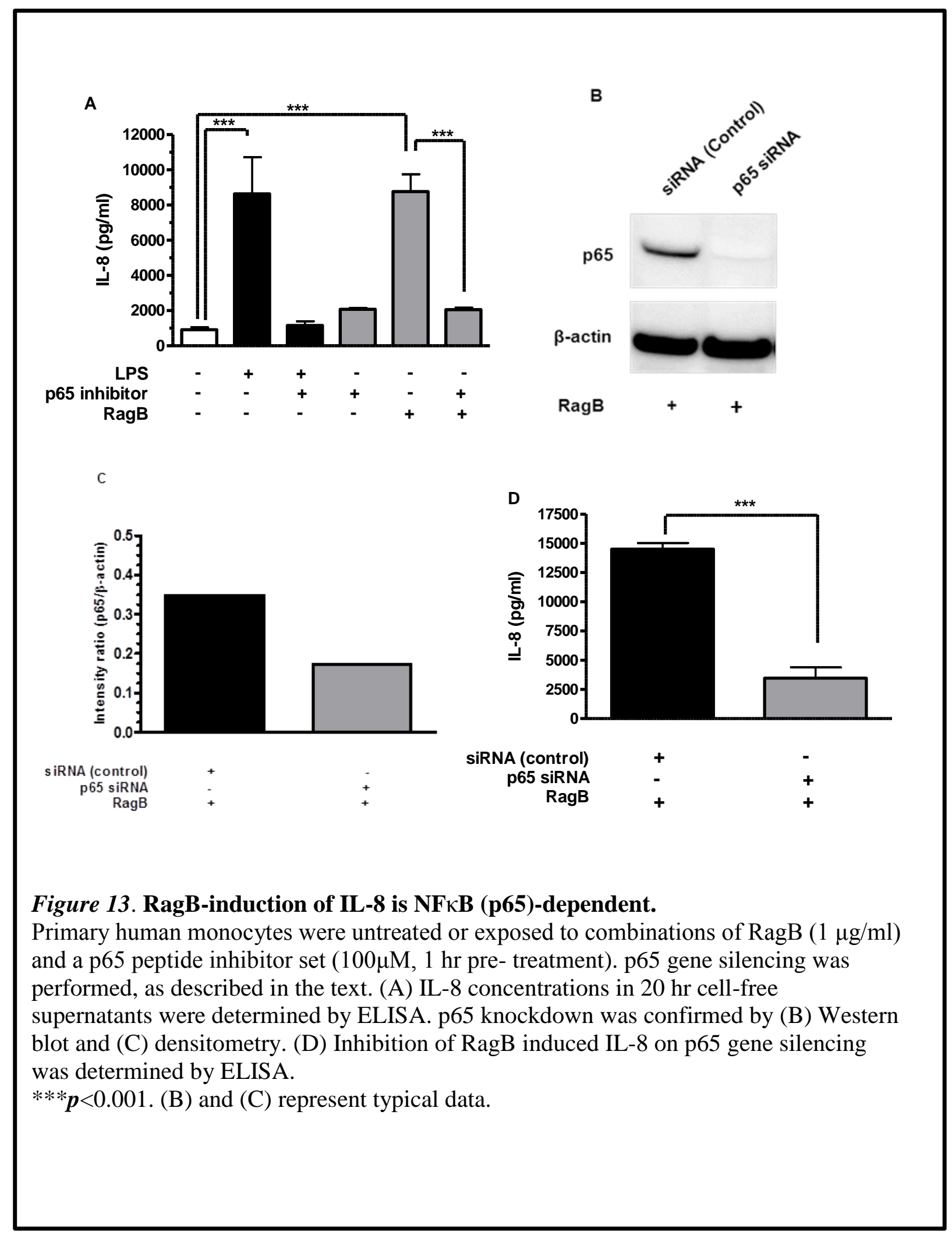




\section{RagB induces phosphorylation of STAT4 and p65}

The phosphorylation of proteins is essential in the regulation of biological pathways including the NFKB (p65) and STAT4 proteins, which become activated once phosphorylated and are able to travel to the nucleus for transcription [103, 104]. To confirm activation of STAT4 and p65, total protein was harvested at $0,15,30,60,90$, 120, and 180 minutes post-RagB $(1 \mu \mathrm{g} / \mathrm{ml})$ stimulation of primary human monocytes. Western blot analysis showed p65 activation as early as 15 minutes post-RagB stimulation with STAT4 phosphorylation occurring shortly after p65 activation (Figure 14). This suggests NFKB may potentially be activating STAT4 once it becomes phosphorylated. A previous study has shown STAT4 to contain NFKB binding sites and is capable of being activated by NFKB [105].

\footnotetext{
p-STAT4

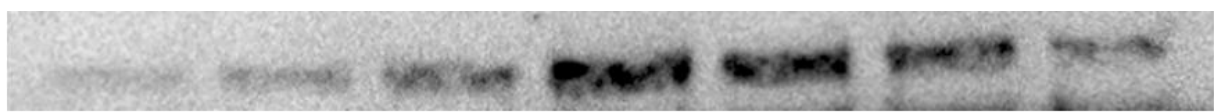

p-p65

$\beta$-actin

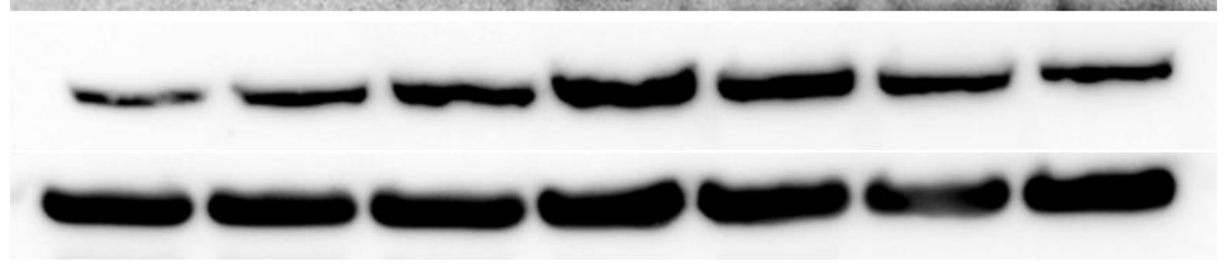

0

15

30

60

90

120

180 mins

Figure 14. RagB induces the phosphorylation of STAT4 and p65.

Primary human monocytes were treated with $1 \mu \mathrm{g} / \mathrm{ml} \mathrm{RagB}$ and total proteins were harvested. Western blot of proteins harvested at $0,15,30,60,90,120$, and 180 mins using STAT4 and p65 phosphorylated antibodies. $\beta$-actin was used as a loading control. Results represent typical data.
} 


\section{$\triangle \operatorname{rag} B$ mutant induces weaker inflammatory response than wild type $P$. gingivalis}

The recombinant form of the RagB protein was shown to induce a strong proinflammatory response in primary human monocytes. However, it is also important to establish the inflammatory potential of RagB in the context of the whole bacterium. W83 wild type, W83 $\triangle \mathrm{rag} B$ and $\operatorname{rag} B$ complemented strains were used to stimulate primary monocytes. A recent study has shown live $P$. gingivalis secretion of gingipains to degrade IL-8 cytokines [106], thus, bacterial cells were fixed in $1 \%$ paraformaldehyde for one hour prior to stimulation to control for cytokine degrading due to gingipains. Monocytes were challenged with bacteria (MOI 1:10) and cell-free supernatants were harvested 20 hours post-stimulation. $\triangle \mathrm{ragB}$ mutants displayed a significant reduction in cytokine response in the context of IL-8 in comparison to both wild type and $\mathrm{rag} B$ complemented bacteria. Similar results were obtained for TNF and IL-6 (Figure 15). Thus, similarly to purified, recombinant $\mathrm{RagB}, \quad \operatorname{ragB}$ appears to induce a robust proinflammatory response in monocytes in the context of the whole bacterium. 


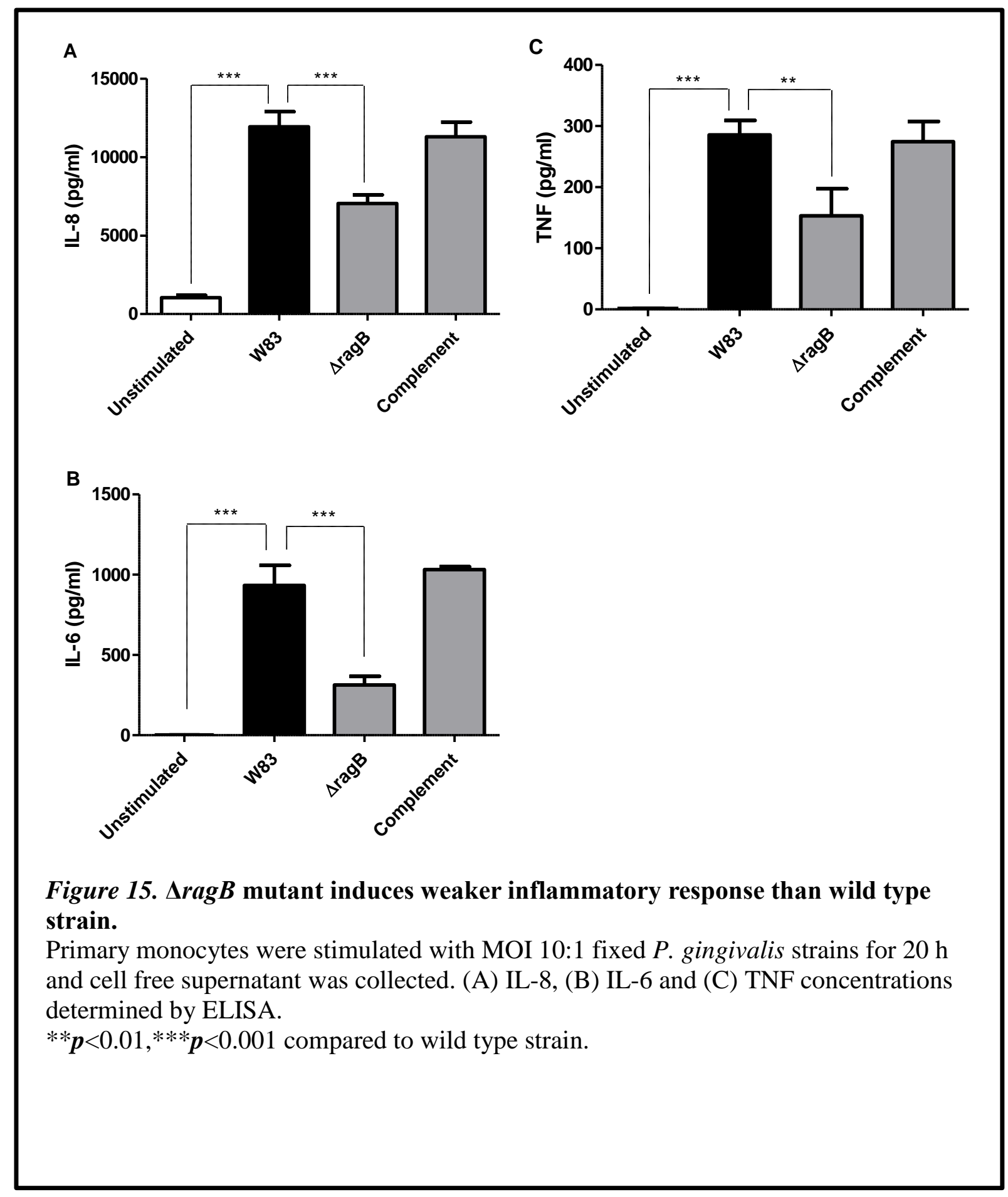




\section{$\triangle \operatorname{rag} B$ mutants are unable to colonize TIGKs}

Previous studies have suggested $\mathrm{rag} B$ to be important in $P$. gingivalis virulence, particularly, epithelial cell invasion. To investigate the contribution of $\operatorname{rag} B$ to cell invasion, we challenged an oral epithelial cell line (TIGK cells) with wild type, $\Delta \mathrm{rag} B$ and complemented $\operatorname{rag} B$ strains. TIGKs were challenged with bacteria for 1 hour then antibiotics were added to kill any remaining extracellular bacteria. After one hour, cells were lysed and plated on GAM/blood agar plates for CFU enumeration. The $\triangle \operatorname{rag} B$ and complemented CFU counts were significantly lower than the parental, wild type strain (Figure 16). This provides evidence that $\mathrm{ragB}$ may play a role in the colonization of host cells.

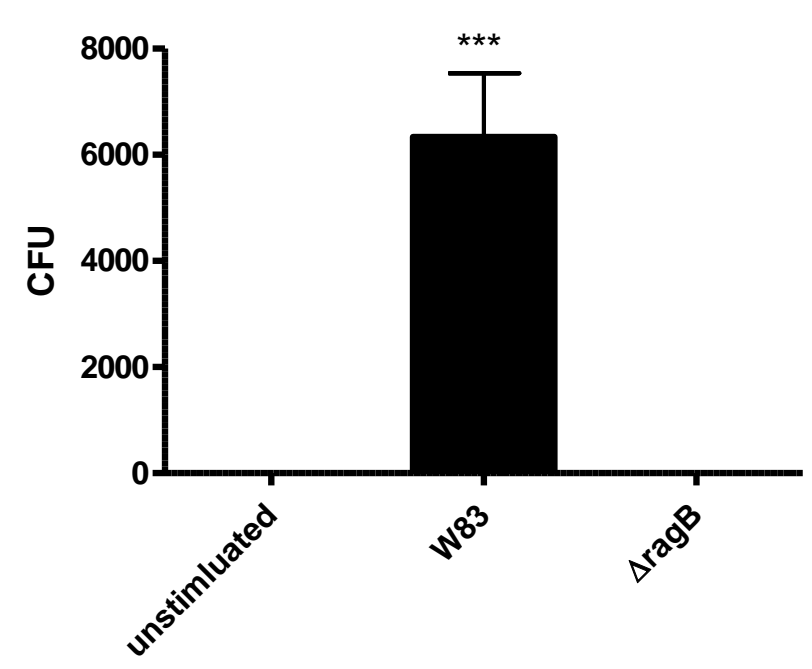

Figure 16. $\triangle \mathrm{ragB}$ mutant exhibits lower colonization rate than wild type in TIGKs. TIGKs were plated in 12 well plate. TIGK cells were unexposed or exposed to W83, $\triangle \mathrm{rag} B$ and complemented strains for $1 \mathrm{hr}$ at MOI 10:1. Cells were washed with PBS and media was replaced with basal media containing gentamicin $(300 \mu \mathrm{g} / \mathrm{ml})$ and metronidazole $(200 \mu \mathrm{g} / \mathrm{ml})$ for $1 \mathrm{hr}$. Cells were then lysed and supernatants were plated on GAM/blood agar and incubated anaerobically at $37^{\circ} \mathrm{C}$ for 7 days. $\mathrm{CFU}$ were then counted.

$* * * \boldsymbol{p}<0.001$ 


\section{Confocal microscope analysis of $P$. gingivalis $\triangle \operatorname{rag} B$ inability to colonize TIGKs}

To investigate the importance of $\operatorname{ragB}$ in epithelial cell colonization, TIGK cells were uninfected or challenged with wild type and $\triangle \mathrm{rag} B$ strains at an MOI of 10:1 for one hour. Antibiotics were used to kill any remaining extracellular bacteria. Cells were then fixed and stained for confocal analysis. The wildtype strain was able to invade, but the $\Delta \operatorname{ragB}$ strain did not appear to be able to colonize the TIGKs (Figure 17). This

combined with colonization assay $\mathrm{CFU}$ counts strongly suggests $\operatorname{rag} B$ plays a role in the colonization of TIGKs. 


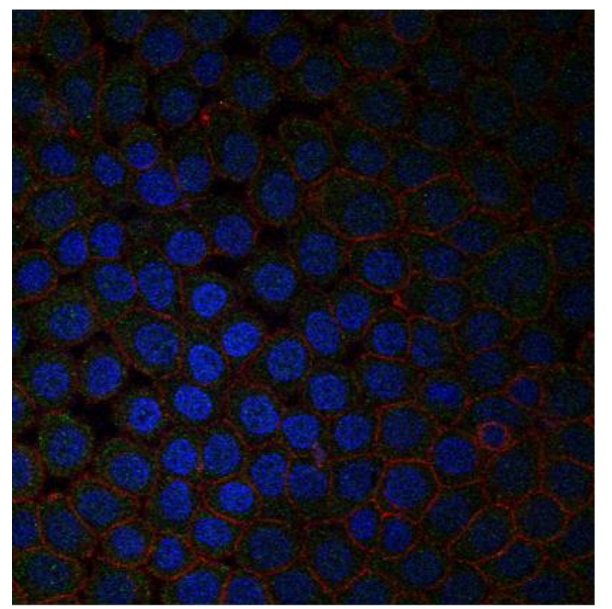

A

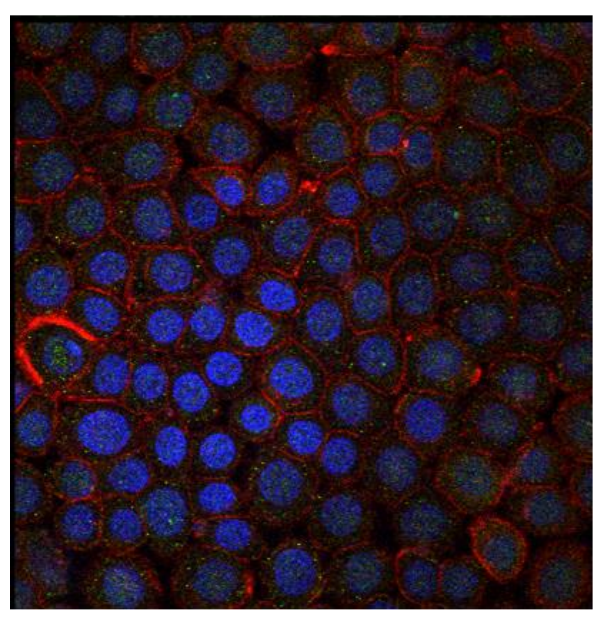

C

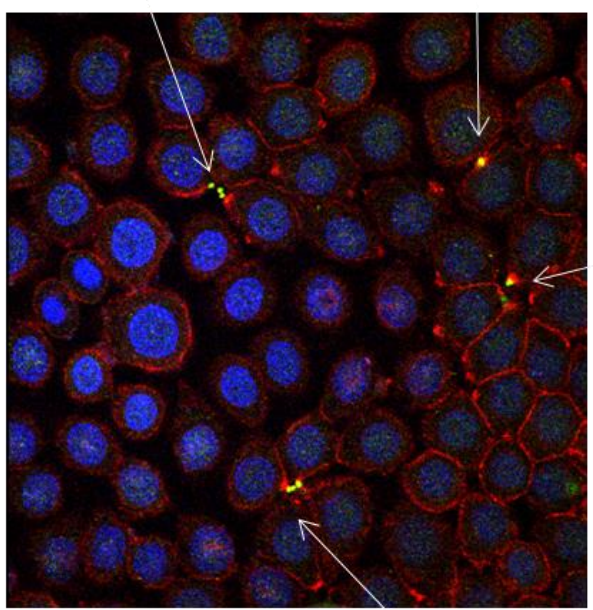

B

Figure 17. ragB appears to play a role in invasion of TIGK cell line.

TIGK cells were (A) unexposed or exposed to (B) W83 and (C) $\Delta \mathrm{rag} B$ strains for $1 \mathrm{hr}$ at MOI 10:1. Cells were washed with PBS and media was replaced with basal media containing gentamicin $(300 \mu \mathrm{g} / \mathrm{ml})$ and metronidazole $(200 \mu \mathrm{g} / \mathrm{ml})$ for $1 \mathrm{hr}$. Cells were then fixed in $4 \%$ paraformaldehyde and stained for confocal. Blue is the DAPI stained nucleus, red is stained actin, and green represents $P$. gingivalis. 


\section{RagB Structure}

RagB was expressed in E.coli TOP10 strain and purified under non-denaturing conditions as previously stated. Thioredoxin is a common tag used in the production of recombinant proteins with no known inflammatory properties [107]. However, for crystallization purposes, it was important to remove the thioredoxin tag, which was achieved by EKMax digestion. Figure 18 represents a 3-D image of the RagB crystal structure using Pymol image software. Identification of active sites and other structure analysis are currently under investigation.

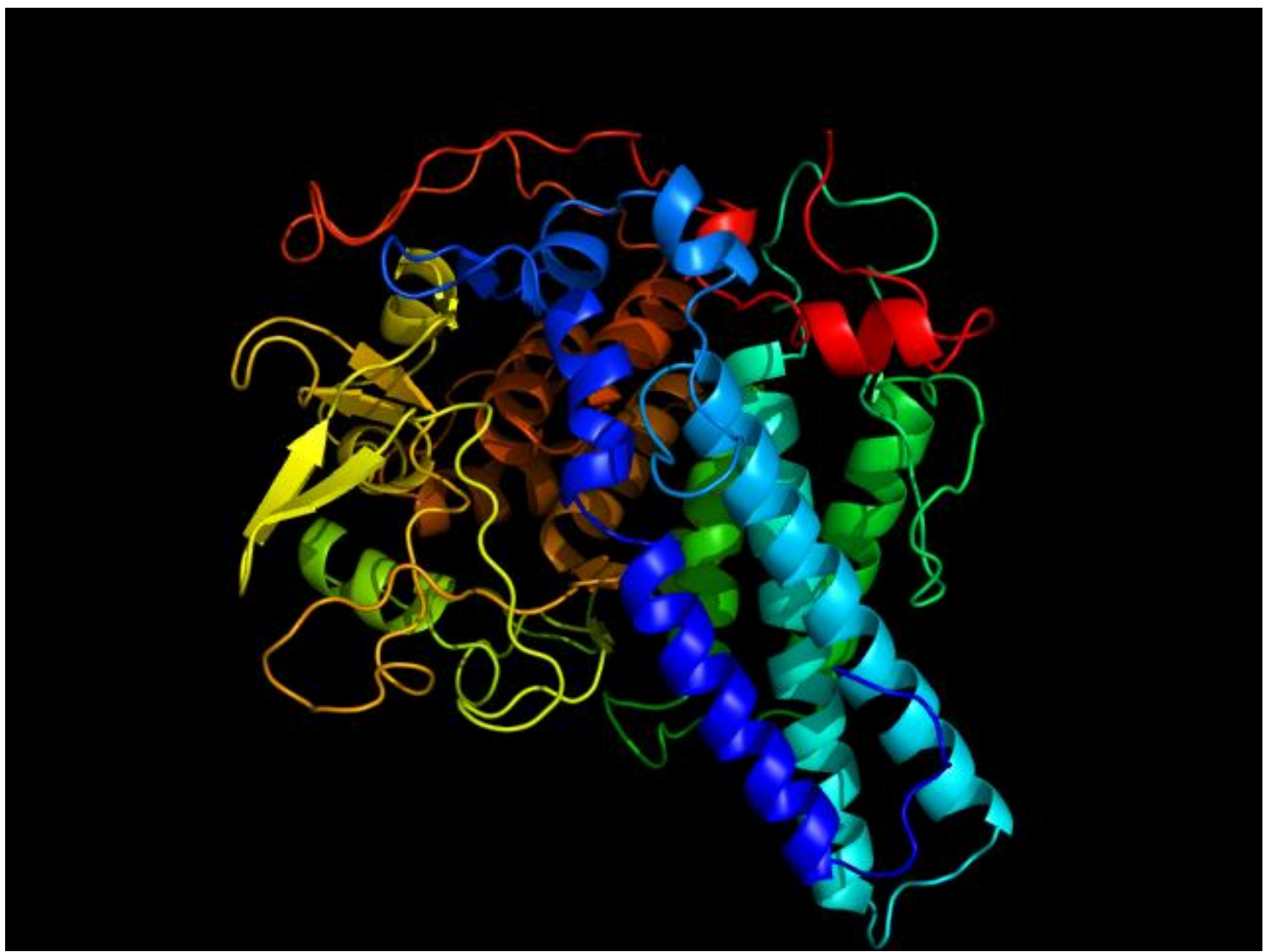

Figure 18. RagB crystal structure. Crystal structure of the $55 \mathrm{kDa}$ outer membrane protein, RagB, from $P$. gingivalis W83. Stereo ribbon diagram of RagB monomer generated in Pymol; color-coded from N-terminus (blue) to the C-terminus (red) 


\section{CHAPTER FOUR: DISCUSSION}

$P$. gingivalis elicits a strong pro-inflammatory response which is thought to represent a critical driving force in the progression of periodontal diseases. This inflammation-driven destruction of host cells and tissues enable $P$. gingivalis to acquire essential nutrients [108]. The $P$. gingivalis armory includes multiple factors that manipulate the innate response, including gingipains, LPS, capsule production, fimbrial proteins and the rag locus. RagB is a predominant, highly antigenic, environmentally regulated, surface-exposed outer membrane protein of $P$. gingivalis. Environmental stimuli also play a role in RagB expression. Tobacco smoke, a major risk factor for periodontitis, suppresses capsule generation, enhances fimbrial protein expression and augments biofilm formation in $P$. gingivalis [109], which may help to explain the increased severity of periodontal diseases observed in smokers. Tobacco smoke is also a potent inducer of RagB expression [109]. RagB expression is also temperature regulated, with increased temperature a hallmark of plaque-induced periodontal inflammation [110].

RagB is homologous to the SusD group of polysaccharide uptake proteins of other Bacteroidetes species, including NanU found in Bacteroides fragilis[111]. A Rag homologue in Bacteroidetes caccae (OmpW) has been associated with inflammatory bowel disease [112]. Subcutaneous inoculation of $\operatorname{rag} B$ mutant $P$. gingivalis into mice resulted in attenuated virulence, assessed by soft tissue lesion size and survival $[74,75]$. 
Furthermore, the ability of RagB mutants to invade transformed epithelial-like cells is curtailed [113]. RagB has also been shown to be associated with more severe forms of disease in patients with periodontitis [70]. Despite such data implicating RagB as an important immunomodulatory molecule, RagB-innate interactions have not been previously examined mechanistically.

We were unable to induce IL-8 or NFKB in the THP-1 cell line with RagB. A recent study concluded THP-1 cells exhibit different inflammatory expression levels than primary human monocytes [114]. In this study, both cell types were stimulated with the TLR4 agonist, LPS, which induced a minimal IL-8 response in THP-1 cells compared to the monocyte expression. Also, IL-6 and IL-10 were not detected in THP-1 cells in response to LPS. This may help to explain why we were unable to detect a inflammatory response to RagB in THP-1 cells. Consequently, we were unable to induce an IL-8 response in TLR transfected HEK cells with RagB stimulation. One possible explanation is the cell line is possibly missing an adapter molecule required for TLR/RagB interactions. Therefore, we decided to use a more relevant cell model by using primary innate cells for our investigations.

We show, for the first time, that RagB is a strong TLR agonist. As has been reported for $P$. gingivalis derived LPS [115], RagB can engage both TLR2 and -4, resulting in the induction of multiple pro-inflammatory cytokines including IL-6, IL-8 and TNF. This innate activation occurs, unusually, in a STAT4-dependent manner, as determined using the pharmaceutical inhibitor, lisofylline, and gene silencing.

STAT4 is best known as an important transcription factor in non-antigenic induction of cytokines in T-cells, type I interferon signaling, and IL-12-mediated 
development of $\mathrm{Th}_{1}$ cells from naïve $\mathrm{CD} 4^{+} \mathrm{T}$ cells $[105,116,117]$. More recently, STAT4 has been shown to be expressed in other immune cells, particularly activated monocytic cells [105]. STAT4 has been suggested as a potential therapeutic target for various inflammatory diseases, including shock [100, 105, 118, 119]. Whole microbial induction of STAT4 expression in innate cells has been established for Mycobacterium tuberculosis and Candida albicans [105]. STAT4 has been reported to bind to MyD88, the TLR-associated signal transducer, and also to the TNF promoter [120]. STAT4 has been shown to result in the induction of IFN $\gamma$ (interferon gamma) in certain cell types and has been shown to be inducible by LPS $[121,122]$. IFN $\gamma$ is a major immune regulator involved in many phases of the immune response including $\mathrm{TH}_{1}$ differentiation and enhancement of antibody production in response to foreign antigens [123, 124]. Indeed, microbial STAT4 activation has been shown to result in the induction of classic NFKBregulated cytokines, but not IFNy, in conventional dendritic cells [105]. Similarly, we could not detect an IFNy signal in RagB exposed monocytic cells, despite STAT4 upregulation (Figure 8). It has been reported that the activation of STAT4 by IL-12, well-defined in T cells, does not occur in innate cells of monocytic lineage [118]. Indeed monocytic cell expression of IL-12 receptors is a scientific disagreement. Grohmann et al. show macrophages express the surface receptor IL-12 [125], but Remoli et al. were unable to induce IL-12 protein expression [105]. The STAT4 promoter contains an NFאB binding site -969/-959 bp upstream from the transcriptional start site that binds p65/p50 and p50/p50 dimers [105]. In addition to STAT4-dependence, RagB induction of pro-inflammatory cytokines requires NFkB (p65), as determined using both pharmaceutical and siRNA approaches. NFkB is the major transcriptional regulator 
associated with TLR activation. Thus, RagB activation of the innate response in human monocytes exhibits both classical and atypical elements of the TLR signaling pathways.

Clearly, recombinant RagB may differ from the natural protein, particularly as it is not anchored in the cell membrane. However, the advantage of using recombinant technology has been long established. Recombinant proteins can be readily purified in large amounts and be free of accessory proteins (such as RagA). It is important to note RagA and RagB are thought to form a protein-protein complex, raising the question of the inflammatory potential to the combined Rag complex.

With this in mind, we also examined cytokine (IL-6, IL-8 and TNF) production in monocytes exposed to WT, $\Delta r a g B$ and complemented $P$. gingivalis strains. These data support a pro-inflammatory role for RagB in the context of the whole bacterium, similar to the recombinant protein. Bacterial cells were pre-fixed in $1 \%$ paraformaldehyde, thus controlling for cytokine destruction by secreted gingipains. Paraformaldehyde has been proven to effectively preserve morphology and surface ultra-structure in bacterial cells [126].

TIGKs were used to determine if RagB plays a role in epithelial cell colonization. TIGKs are a recently developed immortalized epithelial cell line used to study oral bacteria interactions with host gingival cells [127]. It has previously been suggested that the rag locus plays a role in cell invasion based on hybridization arrays comparing invasive and non-invasive strains [113]. Using CFU counts and visualization by confocal, we showed the $\triangle \mathrm{rag} B$ mutant strain was unable to colonize TIGK cells. However, the complemented mutant was unable to restore colonization capability similar to wildtype in TIGKs. We were able to show the complement strain restore 
inflammatory responses to wildtype levels, however, the bacteria were fixed in paraformaldehyde prior to infection. This may be dueto the large size of the complementing vector, or the strain may have become weakened or impaired. P. gingivalis strains do not naturally contain plasmids, thus the plasmid may have impaired intracellular survival. An alternative strategy to complementation would be to reinsert the $\operatorname{rag} B$ gene back into the $\operatorname{srag} B$ mutant strain. Established immunomodulatory virulence factors of $P$. gingivalis include LPS, fimbrial proteins (FimA and Mfa1), capsular polysaccharides and gingipains $[45,51,128]$. It appears that $\mathrm{RagB}$, which induces multiple pro-inflammatory cytokines in a dose-related, TLR-, STAT4- and p65- dependent manner, may now be added to this list, at least as ascertained using recombinant protein and rag-specific mutants.

$\mathrm{RagB}$, is assumed to facilitate polysaccharide, or other nutrient transport, along with RagA. The rag locus is thought to facilitate transport through the periplasmic spanning protein, TonB. RagA is a membrane associated protein that forms a pore like structure in the outer membrane and RagB is an exposed outer membrane protein. It has been previously proposed that rag may aid in ferrous iron transport [68]. Additionally, a study using rag mutants demonstrated a delayed growth rate when compared to wildtype, but similar growth rates with digested media suggesting rag may aid in the transport of larger peptides [74]. rag locus homologs, the sus system found in Bacteroides sp. are involved in sugar uptake [129]. That being said, it is still unclear of the molecules transported by the rag locus of $P$. gingivalis.

Our initial structural analyses of RagB are suggestive of a disaccharide-binding protein (Figure 17). As $P$. gingivalis is considered asaccharolytic, however, the 
physiological relevance of sugar uptake is not immediately transparent, but is likely to be important in, for example, capsule generation or other non-ATP generating metabolic processes. Additionally, $\operatorname{RagB}$, as a promoter of inflammation, is likely to contribute to the availability of protein, required by $P$. gingivalis as a carbon source.

Chronic periodontitis is a major health problem worldwide and is caused by persistent stimulation of the innate response to oral pathogens. Periodontitis is also associated with other diseases such as diabetes, rheumatoid arthritis, and cardiovascular disease. Inflammation occurs when immune cells recognize foreign antigens by PPRs. P. gingivalis, a causative agent in periodontitis, uses multiple virulence factors to establish infection and persist within the host. Dental biofilms typically develop between the tooth and oral epithelium that serve as protective reservoirs for bacteria against the innate immune response. $\operatorname{RagB}$, a major virulence factor of $P$. gingivalis, is commonly associated with severe periodontitis. This thesis investigates the inflammatory potential of RagB and the mechanisms involved. Studies have shown RagB to be the most immune dominant outer membrane antigen of $P$. gingivalis and have associated it with periradicular lesions. We show RagB elicits a pro-inflammatory response in primary monocytes. This finding may aid in the understanding of the inflammatory response to $P$. gingivalis in periodontal diseases. With a clear need for better therapeutics and preventive strategies for periodontal disease, $\mathrm{RagB}$ would serve as a good candidate for further exploration based on inflammatory properties shown herein. 


\section{CHAPTER FIVE: THERAPEUTIC IMPLICATIONS}

\section{Ongoing Investigations:}

Studies involving rag mutants and using the Baker bone loss model are currently ongoing in the Scott lab [130]. The Baker model will be used to measure $\operatorname{rag} A$ and $\operatorname{rag} B$ contribution to bone loss in context of whole bacterium. Bacterial burden of $P$. gingivalis strains in the oral cavity and blood will also be examined. Neutrophil recruitment will also be measured in the oral gingival tissues.

Tn Seq library of $P$. gingivalis has been constructed (JH). The 80,000 colony mutant library pool will be used to identify genes as essential in cigarette smoke exposed (CSE) media, colonization of epithelial cell line and murine abscess models. Highthroughput sequencing has been conducted and data analysis is currently underway.

\section{Pharmacological approaches}

Host inflammatory pathways have been used as targets for controlling periodontal diseases. Adamowicz et al showed that systemic administration of a GSK3 $\beta$-specific inhibitor, SB216763, led to the suppression of $P$. gingivalis-induced pro-inflammatory cytokine production and reduced recruitment of neutrophils, while abolishing periodontal bone loss in mice [131]. Following activation of TLRs in monocytes and PMBCs, 
GSK3 $\beta$ (glycogen synthase kinase-3) has been shown to be necessary for full stimulation of pro-inflammatory cytokines, including IL-6, IL-1 $\beta$ and TNF [132]. We show that RagB signals through TLR2 and -4 and induced pro-inflammatory cytokines in a STAT4and p65-dependent manner.

Therefore, we attempted to use a similar approach of targeting the host inflammatory pathway, in vitro. The STAT4 inhibitor, lisofylline, has been shown to reduce diabetes by controlling IL-12 induction of STAT4 in mice [15]. We show lisofylline reduces the inflammatory response to RagB in vitro, and thus, may have potential in controlling periodontitis in an in vivo model. By identifying inflammatory pathways induced by $P$. gingivalis, new therapeutic targets can be developed.

A potential downside of this approach, targeting host inflammatory pathways, is the suppression of the innate immune response. Targeting the host's immune response is not specific to one particular pathogen, thus, can potentially promote increase susceptibility to infection by immune suppression. Alternatively, a more relevant approach would be to target antigen specific epitopes of pathogens. RagB could potentially serve as target for $P$. gingivalis infections based on its location on the outer membrane surface, host recognition and specificity to $P$. gingivalis.

\section{Implications of a $\operatorname{ragB}$ vaccine:}

The potential of $\operatorname{ragB}$ as a vaccine candidate has been examined by Zheng et.al [76]. A ragB-linked DNA vaccine in mice increased antibody production, reduced lesion size and increased resistance to $P$. gingivalis infection. DNA vaccines are eukaryotic non-replicating expression vectors that can be injected directly into cells, followed by 
expression of the encoded gene which leads to immune activation against the specific antigen being produced [133]. Our data further support targeting RagB as a potential therapeutic agent with which to control $P$. gingivalis-induced inflammatory disease, based on surface availability and pro-inflammatory properties. $P$. gingvalis is a keystone pathogen that causes dysbiosis in the oral microbiome, thus, eliminating $P$. gingivalis could allow the microbiome to restore homeostasis.

However, it must be remembered that there is considerable antigenic variation at the rag locus, with at least four non-cross reactive RagB proteins identified [134]. It is possible, then, that RagB produced by different $P$. gingivalis strains may have altered inflammatory activities and, thus, exhibit differing virulence potential. Indeed, the highly virulent $P$. gingivalis lab strains W83 (used herein) and W50 each carry rag1, which has been clinically associated with deep periodontal pockets, along with $26 \%$ of 168 isolates. The less pathogenic strain, ATCC 33277, carries rag4, along with $14 \%$ of isolates, which cross reacts poorly with W83-specific RagB antibodies [70, 73, 134]. The nucleotide sequences of $\mathrm{ragA}$ and $\mathrm{ragB}$ of 33277 and $\mathrm{W} 83$ are $72 \%$ and 59\% [74]. This may be important in the drive to develop RagB-based vaccines for periodontal disease prevention [76]. Fortunately, DNA vaccines can be constructed to encode multiple genes on one expression plasmid [135]. 


\section{Crystal structure analysis}

The crystal structure of the recombinant RagB is solved and currently being analyzed. The RagB homologs, NanU and SusD, crystal structures have previously been published [111, 129]. RagB is surface exposed which provides a potential therapeutic target. The solved structure analysis could potentially be used to identify proteins or carbohydrates, active sites able to bind sugars for transport and additional host cell receptors capable of binding to RagB. The solved structure may aid in the development of therapeutics towards $P$. gingivalis associated diseases such as inhibitory peptides to block TLR-engagement of RagB or potentially to block attachment to host cells. Though the exact role/s RagB contributes to bacterial survival in vivo has yet to be eluted, RagB does appear to play a major role in virulence and could serve as a potential therapeutic agent.

Viruelnce models of $\boldsymbol{P}$. gingivalisIt has been shown that $P$. gingivalis has the ability to invade and colonize epithelial cells. This allows $P$. gingivalis to persist and to avoid destruction from the host's immune response. Previous studies, through the use of hybridization arrays, have shown the rag locus to be a potential virulence factor in invasion. It has recently been shown the rag locus to be essential for viability in vitro using a mariner transposon system in $P$. gingivalis strain 33277 [72]. RagB may aid $P$. gingivalis in attachment to the host, modification of host membrane proteins for internalization, or survival once internalized within the host cell. We show ragB mutants 
were unable to colonize the immortalized oral epithelial cell line, TIGK, using an antibiotic protection assay. The exact role $\operatorname{rag} B$ plays in invasion is still unknown and additional experiments are required. One approach would be to use fluorescent labeled $P$. gingivalis to infect TIGKs using confocal microscopy to visualize interactions in realtime. An alternative approach would be to perform an invasion assay without the use of antibiotics, and count CFUs to determine if $\operatorname{ragB}$ aids in attachment. RagB may potentially be used as a target to block entry and/or attachment to host cells.

Two previous studies have examined rag mutants using murine soft tissue models, which are used to measure inflammatory potential of bacterial strains injected dorsal subcutaneously. They showed rag mutants displayed a reduction in inflammatory lesion size, lower CFU recovery in the spleen and increased mice survival rate when compared to the wild type strain $[74,75]$. These results correlate with our study, demonstrating the $\operatorname{rag} B$ mutant exhibits a reduction in inflammatory potential compared to the parental strain.

An alternative in vivo model available is the alveolar bone loss model [130]. The bone loss model allows for investigations of bacterial induced bone-loss in the oral cavity, bacterial burden of the oral cavity, neutrophil recruitment in the gingival tissue and systemic inflammatory mediators in the blood. Additionally, murine dorsal subcutaneous chamber model can be utilized to measure inflammatory responses to agonists of interest. Metal chambers are implanted in the backs of mice that allow for an environment in which to measure cytokine production, neutrophil infiltration, and bacterial growth within the chamber [136]. The rag mutants would be a good candidate 
for both models. We would be able to determine the inflammatory potential of rag genes in an in vivo model and the role rag plays in the progression of periodontitis.

\section{Summary}

In summary, RagB is a major pro-inflammatory protein of $P$. gingivalis that is recognized by human TLR2 and TLR4. We have shown RagB to induce proinflammatory cytokines in a p65 and STAT4 dependent manner. We also show the inflammatory potential of $\operatorname{rag} B$ in context of the whole bacterium. The exact role RagB contributes in bacterial physiology is still unknown, although, we hope the crystal structure yields targets of interest for future investigations. We also show RagB plays a potentially major role in the colonization of TIGK cells which warrants further investigation into the mechanisms involved. We conclude RagB is a major virulence factor of $P$. gingivalis and may serve as a potential therapeutic target for $P$. gingivalis induced diseases. 


\section{REFERENCES}

1. Ray, A. and K.E. Prefontaine, Physical association and functional antagonism between the 065 subunit of transcription factor NF-kappa B and the glucocorticoid receptor. Proceedings of the National Academy of Sciences of the United States of America, 1994. 91(2): p. 752-6.

2. Sternberg, E.M., Neural regulation of innate immunity: a coordinated nonspecific host response to pathogens. Nature reviews. Immunology, 2006. 6(4): p. 318-28.

3. Straub, R.H., et al., Energy regulation and neuroendocrine-immune control in chronic inflammatory diseases. Journal of internal medicine, 2010. 267(6): p. 543-60.

4. $\quad$ Ogden, C.L., et al., Prevalence of childhood and adult obesity in the United States, 2011-2012. JAMA, 2014. 311(8): p. 806-14.

5. Yamamoto, Y. and R.B. Gaynor, Therapeutic potential of inhibition of the NFkappaB pathway in the treatment of inflammation and cancer. The Journal of clinical investigation, 2001. 107(2): p. 135-42.

6. Madonna, G., et al., NF-kappaB as potential target in the treatment of melanoma. Journal of translational medicine, 2012. 10: p. 53.

7. Ciarcia, R., et al., Imatinib treatment inhibit IL-6, IL-8, NF-KB and AP-1 production and modulate intracellular calcium in CML patients. Journal of cellular physiology, 2012. 227(6): p. 2798-803.

8. Capiralla, H., et al., Resveratrol mitigates lipopolysaccharide- and Abetamediated microglial inflammation by inhibiting the TLR4/NF-kappaB/STAT signaling cascade. J Neurochem, 2012. 120(3): p. 461-72.

9. de Goer de Herve, M.G., et al., Interferon-alpha triggers B cell effector 1 (Be1) commitment. PLoS One, 2011. 6(4): p. e19366.

10. O'Malley, J.T., et al., Signal transducer and activator of transcription 4 limits the development of adaptive regulatory T cells. Immunology, 2009. 127(4): p. 58795.

11. Walker, J.G., et al., Characterisation of a dendritic cell subset in synovial tissue which strongly expresses Jak/STAT transcription factors from patients with rheumatoid arthritis. Ann Rheum Dis, 2007. 66(8): p. 992-9.

12. O'Malley, J.T., et al., STAT4 isoforms differentially regulate Th1 cytokine production and the severity of inflammatory bowel disease. J Immunol, 2008. 181(7): p. 5062-70.

13. Yang, Z., et al., Autoimmune diabetes is blocked in Stat4-deficient mice. J Autoimmun, 2004. 22(3): p. 191-200.

14. Chen, M., et al., Lisofylline, a novel antiinflammatory agent, protects pancreatic beta-cells from proinflammatory cytokine damage by promoting mitochondrial metabolism. Endocrinology, 2002. 143(6): p. 2341-8.

15. Yang, Z., et al., The novel anti-inflammatory compound, lisofylline, prevents diabetes in multiple low-dose streptozotocin-treated mice. Pancreas, 2003. 26(4): p. e99-104.

16. Petersen, P.E., et al., The global burden of oral diseases and risks to oral health. Bull World Health Organ, 2005. 83(9): p. 661-9. 
17. Brown, L.J., B.A. Johns, and T.P. Wall, The economics of periodontal diseases. Periodontology 2000, 2002. 29: p. 223-34.

18. Brown, L.J. and H. Loe, Prevalence, extent, severity and progression of periodontal disease. Periodontology 2000, 1993. 2: p. 57-71.

19. Eke, P.I., et al., Prevalence of periodontitis in adults in the United States: 2009 and 2010. Journal of dental research, 2012. 91(10): p. 914-20.

20. Kinane, D.F. and I.G. Chestnutt, Relationship of diabetes to periodontitis. Current opinion in periodontology, 1997. 4: p. 29-34.

21. Bergstrom, J., Cigarette smoking as risk factor in chronic periodontal disease. Community dentistry and oral epidemiology, 1989. 17(5): p. 245-7.

22. Tanner, A.C., et al., Clinical and other risk indicators for early periodontitis in adults. Journal of periodontology, 2005. 76(4): p. 573-81.

23. Van Dyke, T.E. and D. Sheilesh, Risk factors for periodontitis. Journal of the International Academy of Periodontology, 2005. 7(1): p. 3-7.

24. Calsina, G., J.M. Ramon, and J.J. Echeverria, Effects of smoking on periodontal tissues. Journal of clinical periodontology, 2002. 29(8): p. 771-6.

25. Baljoon, M., S. Natto, and J. Bergstrom, Long-term effect of smoking on vertical periodontal bone loss. Journal of clinical periodontology, 2005. 32(7): p. 789-97.

26. Kumar, P.S., et al., Tobacco smoking affects bacterial acquisition and colonization in oral biofilms. Infection and immunity, 2011. 79(11): p. 4730-8.

27. Marsh, P.D., Microbial ecology of dental plaque and its significance in health and disease. Advances in dental research, 1994. 8(2): p. 263-71.

28. Palmer, R.J., Jr., et al., Mutualism versus independence: strategies of mixedspecies oral biofilms in vitro using saliva as the sole nutrient source. Infection and immunity, 2001. 69(9): p. 5794-804.

29. Bradshaw, D.J., et al., Effect of oxygen, inoculum composition and flow rate on development of mixed-culture oral biofilms. Microbiology, 1996. 142 ( Pt 3): p. 623-9.

30. Scannapieco, F.A., R.B. Bush, and S. Paju, Associations between periodontal disease and risk for atherosclerosis, cardiovascular disease, and stroke. A systematic review. Annals of periodontology / the American Academy of Periodontology, 2003. 8(1): p. 38-53.

31. Demmer, R.T. and M. Desvarieux, Periodontal infections and cardiovascular disease: the heart of the matter. Journal of the American Dental Association, 2006. 137 Suppl: p. 14S-20S; quiz 38S.

32. Paju, S. and F.A. Scannapieco, Oral biofilms, periodontitis, and pulmonary infections. Oral diseases, 2007. 13(6): p. 508-12.

33. Bansal, M., M. Khatri, and V. Taneja, Potential role of periodontal infection in respiratory diseases - a review. Journal of medicine and life, 2013. 6(3): p. 244-8.

34. Detert, J., et al., The association between rheumatoid arthritis and periodontal disease. Arthritis research \& therapy, 2010. 12(5): p. 218.

35. Saini, R., S. Saini, and S.R. Saini, Periodontitis: A risk for delivery of premature labor and low-birth-weight infants. Journal of natural science, biology, and medicine, 2010. 1(1): p. 40-2.

36. Ikegami, A., P. Chung, and Y.W. Han, Complementation of the fadA mutation in Fusobacterium nucleatum demonstrates that the surface-exposed adhesin 
promotes cellular invasion and placental colonization. Infection and immunity, 2009. 77(7): p. 3075-9.

37. Shanthi, V., et al., Association of pregnant women periodontal status to preterm and low-birth weight babies: A systematic and evidence-based review. Dental research journal, 2012. 9(4): p. 368-80.

38. Holt, S.C. and J.L. Ebersole, Porphyromonas gingivalis, Treponema denticola, and Tannerella forsythia: the "red complex", a prototype polybacterial pathogenic consortium in periodontitis. Periodontology 2000, 2005. 38: p. 72122.

39. Hajishengallis, G., et al., Low-abundance biofilm species orchestrates inflammatory periodontal disease through the commensal microbiota and complement. Cell host \& microbe, 2011. 10(5): p. 497-506.

40. Maekawa, T., et al., Porphyromonas gingivalis manipulates complement and TLR signaling to uncouple bacterial clearance from inflammation and promote dysbiosis. Cell Host Microbe, 2014. 15(6): p. 768-78.

41. Hajishengallis, G., R.P. Darveau, and M.A. Curtis, The keystone-pathogen hypothesis. Nature reviews. Microbiology, 2012.

42. Shapira, L., S. Ayalon, and T. Brenner, Effects of Porphyromonas gingivalis on the central nervous system: activation of glial cells and exacerbation of experimental autoimmune encephalomyelitis. Journal of periodontology, 2002. 73(5): p. 511-6.

43. Imamura, T., The role of gingipains in the pathogenesis of periodontal disease. Journal of periodontology, 2003. 74(1): p. 111-8.

44. Shah, H.N. and S.E. Gharbia, Ecological events in subgingival dental plaque with reference to Bacteroides and Fusobacterium species. Infection, 1989. 17(4): p. 264-8.

45. Holt, S.C., et al., Virulence factors of Porphyromonas gingivalis. Periodontol 2000, 1999. 20: p. 168-238.

46. Laine, M.L., B.J. Appelmelk, and A.J. van Winkelhoff, Novel polysaccharide capsular serotypes in Porphyromonas gingivalis. J Periodontal Res, 1996. 31(4): p. 278-84.

47. van Winkelhoff, A.J., et al., K-antigens in Porphyromonas gingivalis are associated with virulence. Oral Microbiol Immunol, 1993. 8(5): p. 259-65.

48. Vernal, R., et al., Distinct human T-lymphocyte responses triggered by Porphyromonas gingivalis capsular serotypes. J Clin Periodontol, 2014. 41(1): p. 19-30.

49. Irshad, M., et al., In vitro invasion and survival of Porphyromonas gingivalis in gingival fibroblasts; role of the capsule. Arch Immunol Ther Exp (Warsz), 2012. 60(6): p. 469-76.

50. Singh, A., et al., The capsule of Porphyromonas gingivalis leads to a reduction in the host inflammatory response, evasion of phagocytosis, and increase in virulence. Infect Immun, 2011. 79(11): p. 4533-42.

51. Potempa, J., R. Pike, and J. Travis, The multiple forms of trypsin-like activity present in various strains of Porphyromonas gingivalis are due to the presence of either Arg-gingipain or Lys-gingipain. Infection and immunity, 1995. 63(4): p. 1176-82. 
52. Nakayama, K., et al., Construction and characterization of arginine-specific cysteine proteinase (Arg-gingipain)-deficient mutants of Porphyromonas gingivalis. Evidence for significant contribution of Arg-gingipain to virulence. The Journal of biological chemistry, 1995. 270(40): p. 23619-26.

53. Bao, K., et al., Role of Porphyromonas gingivalis gingipains in multi-species biofilm formation. BMC microbiology, 2014. 14: p. 258.

54. Yamatake, K., et al., Role for gingipains in Porphyromonas gingivalis traffic to phagolysosomes and survival in human aortic endothelial cells. Infect Immun, 2007. 75(5): p. 2090-100.

55. Popadiak, K., et al., Biphasic effect of gingipains from Porphyromonas gingivalis on the human complement system. J Immunol, 2007. 178(11): p. 7242-50.

56. Sugawara, S., et al., Proteolysis of human monocyte CD14 by cysteine proteinases (gingipains) from Porphyromonas gingivalis leading to lipopolysaccharide hyporesponsiveness. J Immunol, 2000. 165(1): p. 411-8.

57. Kumada, H., et al., Structural study on the free lipid A isolated from lipopolysaccharide of Porphyromonas gingivalis. Journal of bacteriology, 1995. 177(8): p. 2098-106.

58. Darveau, R.P., et al., Porphyromonas gingivalis lipopolysaccharide contains multiple lipid A species that functionally interact with both toll-like receptors 2 and 4. Infection and immunity, 2004. 72(9): p. 5041-51.

59. Herath, T.D., et al., Tetra- and penta-acylated lipid A structures of Porphyromonas gingivalis LPS differentially activate TLR4-mediated NF-kappaB signal transduction cascade and immuno-inflammatory response in human gingival fibroblasts. PLoS One, 2013. 8(3): p. e58496.

60. Herath, T.D., et al., Porphyromonas gingivalis lipopolysaccharide lipid A heterogeneity differentially modulates the expression of IL-6 and IL-8 in human gingival fibroblasts. J Clin Periodontol, 2011. 38(8): p. 694-701.

61. Hamada, N., et al., Isolation and characterization of a minor fimbria from Porphyromonas gingivalis. Infection and immunity, 1996. 64(11): p. 4788-94.

62. Hamada, N., et al., Construction and characterization of a fimA mutant of Porphyromonas gingivalis. Infection and immunity, 1994. 62(5): p. 1696-704.

63. Njoroge, T., et al., A role for fimbriae in Porphyromonas gingivalis invasion of oral epithelial cells. Infect Immun, 1997. 65(5): p. 1980-4.

64. Wright, C.J., et al., Disruption of heterotypic community development by Porphyromonas gingivalis with small molecule inhibitors. Mol Oral Microbiol, 2014. 29(5): p. 185-93.

65. Bagaitkar, J., et al., Tobacco upregulates $P$. gingivalis fimbrial proteins which induce TLR2 hyposensitivity. PloS one, 2010. 5(5): p. e9323.

66. Hajishengallis, G., M. Wang, and S. Liang, Induction of distinct TLR2-mediated proinflammatory and proadhesive signaling pathways in response to Porphyromonas gingivalis fimbriae. J Immunol, 2009. 182(11): p. 6690-6.

67. Zeituni, A.E., et al., The native 67-kilodalton minor fimbria of Porphyromonas gingivalis is a novel glycoprotein with DC-SIGN-targeting motifs. J Bacteriol, 2010. 192(16): p. 4103-10. 
68. Curtis, M.A., S.A. Hanley, and J. Aduse-Opoku, The rag locus of Porphyromonas gingivalis: a novel pathogenicity island. Journal of periodontal research, 1999. 34(7): p. 400-5.

69. Reeves, A.R., et al., A Bacteroides thetaiotaomicron outer membrane protein that is essential for utilization of maltooligosaccharides and starch. Journal of bacteriology, 1996. 178(3): p. 823-30.

70. Hanley, S.A., J. Aduse-Opoku, and M.A. Curtis, A 55-kilodalton immunodominant antigen of Porphyromonas gingivalis W50 has arisen via horizontal gene transfer. Infection and immunity, 1999. 67(3): p. 1157-71.

71. Curtis, M.A., et al., Identification of the major surface protein antigens of Porphyromonas gingivalis using IgG antibody reactivity of periodontal casecontrol serum. Oral microbiology and immunology, 1991. 6(6): p. 321-6.

72. Klein, B.A., et al., Identification of essential genes of the periodontal pathogen Porphyromonas gingivalis. BMC Genomics, 2012. 13: p. 578.

73. Imai, M., et al., Major outer membrane proteins from Porphyromonas gingivalis: strain variation, distribution, and clinical significance in periradicular lesions. European journal of oral sciences, 2005. 113(5): p. 391-9.

74. Nagano, K., et al., Characterization of RagA and RagB in Porphyromonas gingivalis: study using gene-deletion mutants. Journal of medical microbiology, 2007. 56(Pt 11): p. 1536-48.

75. Shi, X., et al., The rag locus of Porphyromonas gingivalis contributes to virulence in a murine model of soft tissue destruction. Infection and immunity, 2007. 75(4): p. 2071-4.

76. Zheng, D., et al., Enhancing specific-antibody production to the ragB vaccine with GITRL that expand Tfh, IFN-gamma $(+) T$ cells and attenuates Porphyromonas gingivalis infection in mice. PloS one, 2013. 8(4): p. e59604.

77. Rodrigues, P.H. and A. Progulske-Fox, Gene expression profile analysis of Porphyromonas gingivalis during invasion of human coronary artery endothelial cells. Infection and immunity, 2005. 73(9): p. 6169-73.

78. Mackey, D. and A.J. McFall, MAMPs and MIMPs: proposed classifications for inducers of innate immunity. Molecular microbiology, 2006. 61(6): p. 1365-71.

79. Zelensky, A.N. and J.E. Gready, The C-type lectin-like domain superfamily. The FEBS journal, 2005. 272(24): p. 6179-217.

80. Ye, Z. and J.P. Ting, NLR, the nucleotide-binding domain leucine-rich repeat containing gene family. Current opinion in immunology, 2008. 20(1): p. 3-9.

81. Onoguchi, K., M. Yoneyama, and T. Fujita, Retinoic acid-inducible gene-I-like receptors. Journal of interferon \& cytokine research : the official journal of the International Society for Interferon and Cytokine Research, 2011. 31(1): p. 27-31.

82. Medzhitov, R., Toll-like receptors and innate immunity. Nature reviews. Immunology, 2001. 1(2): p. 135-45.

83. Janeway, C.A., Jr. and R. Medzhitov, Innate immune recognition. Annual review of immunology, 2002. 20: p. 197-216.

84. Rakoff-Nahoum, S. and R. Medzhitov, Toll-like receptors and cancer. Nature reviews. Cancer, 2009. 9(1): p. 57-63. 
85. Chow, J.C., et al., Toll-like receptor-4 mediates lipopolysaccharide-induced signal transduction. The Journal of biological chemistry, 1999. 274(16): p. 10689-92.

86. Yoneda, K., et al., Dual topology of functional Toll-like receptor 3 expression in human hepatocellular carcinoma: differential signaling mechanisms of TLR3induced NF-kappaB activation and apoptosis. International journal of oncology, 2008. 33(5): p. 929-36.

87. Yamamoto, M., et al., Role of adaptor TRIF in the MyD88-independent toll-like receptor signaling pathway. Science, 2003. 301(5633): p. 640-3.

88. Vallabhapurapu, S. and M. Karin, Regulation and function of NF-kappaB transcription factors in the immune system. Annual review of immunology, 2009. 27: p. 693-733.

89. Kagan, J.C., et al., TRAM couples endocytosis of Toll-like receptor 4 to the induction of interferon-beta. Nature immunology, 2008. 9(4): p. 361-8.

90. Akira, S., S. Uematsu, and O. Takeuchi, Pathogen recognition and innate immunity. Cell, 2006. 124(4): p. 783-801.

91. Takeda, K. and S. Akira, Toll-like receptors in innate immunity. International immunology, 2005. 17(1): p. 1-14.

92. Takeda, K., Evolution and integration of innate immune recognition systems: the Toll-like receptors. Journal of endotoxin research, 2005. 11(1): p. 51-5.

93. Duesbery, N.S., et al., Proteolytic inactivation of MAP-kinase-kinase by anthrax lethal factor. Science, 1998. 280(5364): p. 734-7.

94. Sanada, T., et al., The Shigella flexneri effector OspI deamidates UBC13 to dampen the inflammatory response. Nature, 2012. 483(7391): p. 623-6.

95. Zhang, Z., et al., The role of C-terminal tyrosine phosphorylation in the regulation of SHP-1 explored via expressed protein ligation. The Journal of biological chemistry, 2003. 278(7): p. 4668-74.

96. Goodman, A.L., et al., Identifying genetic determinants needed to establish a human gut symbiont in its habitat. Cell Host Microbe, 2009. 6(3): p. 279-89.

97. O'Hara, A.M., et al., Tumor necrosis factor (TNF)-alpha-induced IL-8 expression in gastric epithelial cells: role of reactive oxygen species and AP endonuclease1/redox factor (Ref)-1. Cytokine, 2009. 46(3): p. 359-69.

98. Livak, K.J. and T.D. Schmittgen, Analysis of relative gene expression data using real-time quantitative PCR and the 2(-Delta Delta C(T)) Method. Methods, 2001. 25(4): p. 402-8.

99. Zhang, P., et al., TLR2-dependent modulation of osteoclastogenesis by Porphyromonas gingivalis through differential induction of NFATc1 and NFkappaB. J Biol Chem, 2011. 286(27): p. 24159-69.

100. Kim, H.S. and D.H. Chung, TLR4-mediated IL-12 production enhances IFNgamma and IL-1beta production, which inhibits TGF-beta production and promotes antibody-induced joint inflammation. Arthritis Res Ther, 2012. 14(5): p. R210.

101. Gibson, F.C., 3rd and C.A. Genco, Porphyromonas gingivalis mediated periodontal disease and atherosclerosis: disparate diseases with commonalities in pathogenesis through TLRs. Current pharmaceutical design, 2007. 13(36): p. 3665-75. 
102. Fukao, T., et al., Inducible expression of Stat4 in dendritic cells and macrophages and its critical role in innate and adaptive immune responses. J Immunol, 2001. 166(7): p. 4446-55.

103. Hochrainer, K., G. Racchumi, and J. Anrather, Site-specific phosphorylation of the p65 protein subunit mediates selective gene expression by differential NFkappaB and RNA polymerase II promoter recruitment. J Biol Chem, 2013. 288(1): p. 285-93.

104. Morinobu, A., et al., STAT4 serine phosphorylation is critical for IL-12-induced IFN-gamma production but not for cell proliferation. Proc Natl Acad Sci U S A, 2002. 99(19): p. 12281-6.

105. Remoli, M.E., et al., NF-\{kappa\}B is required for STAT-4 expression during dendritic cell maturation. Journal of leukocyte biology, 2007. 81(1): p. 355-63.

106. Jayaprakash, K., H. Khalaf, and T. Bengtsson, Gingipains from Porphyromonas gingivalis play a significant role in induction and regulation of CXCL8 in THP-1 cells. BMC Microbiol, 2014. 14: p. 193.

107. Jiang, S.J., et al., Identification and characterization of Chlamydia pneumoniaespecific proteins that activate tumor necrosis factor alpha production in $R A W$ 264.7 murine macrophages. Infect Immun, 2008. 76(4): p. 1558-64.

108. Anaya-Bergman, C., et al., Porphyromonas gingivalis ferrous iron transporter FeoB1 influences sensitivity to oxidative stress. Infect Immun, 2010. 78(2): p. 688-96.

109. Bagaitkar, J., et al., Tobacco-induced alterations to Porphyromonas gingivalishost interactions. Environmental microbiology, 2009. 11(5): p. 1242-53.

110. Bonass, W.A., et al., Identification of ragAB as a temperature-regulated operon of Porphyromonas gingivalis W50 using differential display of randomly primed RNA. Infection and immunity, 2000. 68(7): p. 4012-7.

111. Phansopa, C., et al., Structural and functional characterization of NanU, a novel high-affinity sialic acid-inducible binding protein of oral and gut-dwelling Bacteroidetes species. The Biochemical journal, 2014. 458(3): p. 499-511.

112. Wei, B., et al., Molecular cloning of a Bacteroides caccae TonB-linked outer membrane protein identified by an inflammatory bowel disease marker antibody. Infection and immunity, 2001. 69(10): p. 6044-54.

113. Dolgilevich, S., et al., Genomic comparison of invasive and rare non-invasive strains reveals Porphyromonas gingivalis genetic polymorphisms. Journal of oral microbiology, 2011. 3.

114. Schildberger, A., et al., Monocytes, peripheral blood mononuclear cells, and THP-1 cells exhibit different cytokine expression patterns following stimulation with lipopolysaccharide. Mediators Inflamm, 2013. 2013: p. 697972.

115. Ding, P.H., et al., Porphyromonas gingivalis LPS stimulates the expression of LPS-binding protein in human oral keratinocytes in vitro. Innate Immun, 2013. 19(1): p. 66-75.

116. Ronnblom, L., The type I interferon system in the etiopathogenesis of autoimmune diseases. Upsala journal of medical sciences, 2011. 116(4): p. 227-37.

117. Guo, L., et al., IL-1 family members and STAT activators induce cytokine production by Th2, Th17, and Th1 cells. Proceedings of the National Academy of Sciences of the United States of America, 2009. 106(32): p. 13463-8. 
118. Frucht, D.M., et al., Stat4 is expressed in activated peripheral blood monocytes, dendritic cells, and macrophages at sites of Th1-mediated inflammation. $\mathrm{J}$ Immunol, 2000. 164(9): p. 4659-64.

119. Matsukawa, A., et al., Pivotal role of signal transducer and activator of transcription (Stat)4 and Stat6 in the innate immune response during sepsis. The Journal of experimental medicine, 2001. 193(6): p. 679-88.

120. Good, S.R., et al., Temporal induction pattern of STAT4 target genes defines potential for Th1 lineage-specific programming. Journal of immunology, 2009. 183(6): p. 3839-47.

121. Lawless, V.A., et al., Stat4 regulates multiple components of IFN-gammainducing signaling pathways. J Immunol, 2000. 165(12): p. 6803-8.

122. Negishi, M., et al., Lipopolysaccharide (LPS)-induced Interferon (IFN)-gamma production by decidual mononuclear cells (DMNC) is interleukin (IL)-2 and IL12 dependent. Am J Reprod Immunol, 2011. 65(1): p. 20-7.

123. Smeltz, R.B., et al., Role of IFN-gamma in Th1 differentiation: IFN-gamma regulates $I L-18 R$ alpha expression by preventing the negative effects of $I L-4$ and by inducing/maintaining IL-12 receptor beta 2 expression. J Immunol, 2002. 168(12): p. 6165-72.

124. Gujer, C., et al., IFN-alpha produced by human plasmacytoid dendritic cells enhances T cell-dependent naive B cell differentiation. J Leukoc Biol, 2011. 89(6): p. 811-21.

125. Grohmann, U., et al., Positive regulatory role of IL-12 in macrophages and modulation by IFN-gamma. Journal of immunology, 2001. 167(1): p. 221-7.

126. Chao, Y. and T. Zhang, Optimization of fixation methods for observation of bacterial cell morphology and surface ultrastructures by atomic force microscopy. Applied microbiology and biotechnology, 2011. 92(2): p. 381-92.

127. Moffatt-Jauregui, C.E., et al., Establishment and characterization of a telomerase immortalized human gingival epithelial cell line. Journal of periodontal research, 2013.

128. Inaba, H., et al., Heterogenic virulence and related factors among clinical isolates of Porphyromonas gingivalis with type II fimbriae. Oral Microbiol Immunol, 2008. 23(1): p. 29-35.

129. Bakolitsa, C., et al., Structure of BT_3984, a member of the SusD/RagB family of nutrient-binding molecules. Acta crystallographica. Section F, Structural biology and crystallization communications, 2010. 66(Pt 10): p. 1274-80.

130. Baker, P.J., R.T. Evans, and D.C. Roopenian, Oral infection with Porphyromonas gingivalis and induced alveolar bone loss in immunocompetent and severe combined immunodeficient mice. Archives of oral biology, 1994. 39(12): p. 103540.

131. Adamowicz, K., et al., Inhibition of GSK3 abolishes bacterial-induced periodontal bone loss in mice. Mol Med, 2012. 18: p. 1190-6.

132. Martin, M., et al., Toll-like receptor-mediated cytokine production is differentially regulated by glycogen synthase kinase 3. Nat Immunol, 2005. 6(8): p. 777-84.

133. Tang, D.C., M. DeVit, and S.A. Johnston, Genetic immunization is a simple method for eliciting an immune response. Nature, 1992. 356(6365): p. 152-4. 
134. Hall, L.M., et al., Sequence diversity and antigenic variation at the rag locus of Porphyromonas gingivalis. Infection and immunity, 2005. 73(7): p. 4253-62.

135. Luckay, A., et al., Effect of plasmid DNA vaccine design and in vivo electroporation on the resulting vaccine-specific immune responses in rhesus macaques. J Virol, 2007. 81(10): p. 5257-69.

136. Lin, Y.Y., et al., Tissue destruction induced by Porphyromonas gingivalis infection in a mouse chamber model is associated with host tumor necrosis factor generation. Infection and immunity, 2005. 73(12): p. 7946-52. 


\section{CURRICULUM VITAE}

\section{Justin Hutcherson}

1511 Regency Woods Rd. Apt. 302

Henrico, VA 23238

Cell: (731) 514-0543

Postdoctoral Fellow, Virginia Commonwealth University

Email: jahutcherson@vcu.edu , hutch1407@gmail.com

\section{Education/Training:}

Postdoctoral Fellow, Virginia Commonwealth University, VA (2015-present)

Ph. D Candidate Microbiology \& Immunology, University of Louisville, KY (20102014)

M.S., Microbiology \& Immunology, University of Louisville, KY (2012)

M.S., Biology, Middle Tennessee State University, Murfreesboro, TN (2008-2010)

B.S., Biology, University of Tennessee at Martin, TN (2004-2008)

\section{$\underline{\text { Research Experience: }}$}

Primary doctoral project: Investigation of host-pathogen interactions in periodontal inflammatory diseases. Including bacterial virulence factors and their role in activation and suppression of the innate immune response.

Skilled in microbiological, immunological, and cell molecular techniques including protein expression and isolation, microarray technology, Tn-Seq, murine model of infection, etc.

Proficient in independent planning and working multiple projects concurrently.

\section{Awards/Honors:}

Treasurer (2013), American International Relations Club (AIRC), University of Louisville, KY

President (2011-2012), Microbiology and Immunology Student Association; invited and organized distinguished speaker - Dr. John Connor, Boston University School of Medicine

Integrated Programs in Biomedical Sciences (IPIBS) Pre-doctoral Fellowship, University of Louisville, 2010-2012 


\section{Mentorship/Teaching Experience:}

Mentorship:

Rajarshi Guhaniyogi, first year dental Master's student (School of Dentistry, University of Louisville), 6/2014-12/2014. "Cannabidiol suppresses the innate immune response to oral pathogens".

Himabindu Gogeneni, second year dental Master's student (School of Dentistry, University of Louisville), 5/2013-12/2014. "Identification of genes essential for the survival of cigarette smoke-exposed Porphyromonas gingivalis".

Lead Graduate Teaching Assistant (2009-2010), Middle Tennessee State University Biology Department; Mentored Graduate Teaching Assistants.

Graduate Teaching Assistant (2008-2010), Middle Tennessee State University Biology Department; Taught undergraduate biology labs.

\section{Volunteer Work:}

Poster Judge (2014), Research Louisville, University of Louisville, Louisville, KY

Poster Judge (2014), Dupont Manual Science Fair, Louisville, KY

Poster Judge (2013), Dupont Manual Science Fair, Louisville, KY

First Responder (2005-2009), Weakly County Ambulance Service, Dresden, TN

Firefighter (2004-2009), Dresden Fire Department, Dresden, TN

\section{Presentations:}

October 2014 Poster presentation, $13^{\text {th }}$ Annual Brown Cancer Center Retreat, Louisville, KY

October 2013 Poster presentation, 12 $2^{\text {th }}$ Annual Brown Cancer Center Retreat, Louisville, KY

September 2013 Poster presentation, Research Louisville, University of Louisville, Louisville, KY

July 2013 Poster presentation at $5^{\text {th }}$ Congress of Federation of European Microbiologists, Leipzig, Germany

March 2013 Oral and Poster Presentation, $5^{\text {th }}$ Annual Graduate Research Symposium, Louisville, KY 
October 2012 Poster presentation, $11^{\text {th }}$ Annual Brown Cancer Center Retreat, Louisville, KY

September 2012 Poster presentation, Research Louisville, University of Louisville, Louisville, KY

April 2010, Poster presentation, Graduate Symposium, Middle Tennessee State University, Murfreesboro, TN

\section{Publications:}

HUTCHERSON JA, GONENI H, YODER-HIMES D, HENDRICKSON EL, HACKETT, LAMONT RJ, SCOTT DA. Comparison of inherently essential genes of Porphyromonas gingivalis identified in two transposon sequencing libraries. FEMS Microbiology Letters. (Manuscript in preparation)

HUTCHERSON JA, SCOTT DA, BAGAITKAR, J. Scratching the surface-tobaccoinduced bacterial biofilms. Tobacco Induced Diseases. 2015 Feb 10;13(1):1

HUTCHERSON JA, BAGAITKAR J, NAGANO K, YOSIMURA, WANG H, SCOTT DA. Porphyromonas gingivalis RagB is a pro-inflammatory STAT4 agonist. Molecular Oral Microbiology. 2015 JAN; DOI: 10.1111/omi.12089

ZELLER I, HUTCHERSON JA, LAMONT RJ,DEMUTH DR, GUMUS P, NIZAM N, BUDUNELI N, SCOTT DA. Smoking alters the antigenicity and infectivity of Porphyromonas gingivalis. Journal of Periodontology, 2014 Jun; 85(6): 837-44. 